\title{
Contributions of the Liquid and Ice Phases to Global Surface Precipitation: Observations and Global Climate Modeling $\mathscr{D}$
}

\author{
ANDREW J. HEYMSFIELD \\ National Center for Atmospheric Research, Boulder, Colorado \\ CARL SCHMITT \\ University of Alaska Fairbanks, Fairbanks, Alaska \\ Chim-Chieh-Jack Chen, Aaron BAnsemer, And Andrew GetTelman \\ National Center for Atmospheric Research, Boulder, Colorado \\ PAUL R. FIELD \\ Met Office, Exeter, and University of Leeds, Leeds, United Kingdom \\ Chuntao LiU \\ Texas A\&M University, Corpus Christi, Texas
}

(Manuscript received 23 December 2019, in final form 29 May 2020)

\begin{abstract}
This study is the first to reach a global view of the precipitation process partitioning, using a combination of satellite and global climate modeling data. The pathways investigated are 1) precipitating ice (ice/snow/graupel) that forms above the freezing level and melts to produce rain $(S)$ followed by additional condensation and collection as the melted precipitating ice falls to the surface $(R) ; 2)$ growth completely through condensation and collection (coalescence), warm rain $(W)$; and 3 ) precipitating ice (primarily snow) that falls to the surface (SS). To quantify the amounts, data from satellite-based radar measurements-CloudSat, GPM, and TRMM-are used, as well as climate model simulations from the Community Atmosphere Model (CAM) and the Met Office Unified Model (UM). Total precipitation amounts and the fraction of the total precipitation amount for each of the pathways is examined latitudinally, regionally, and globally. Carefully examining the contributions from the satellite-based products leads to the conclusion that about $57 \%$ of Earth's precipitation follows pathway $S, 15 \%$ $R, 23 \% \mathrm{~W}$, and $5 \% \mathrm{SS}$, each with an uncertainty of $\pm 5 \%$. The percentages differ significantly from the global climate model results, with the UM indicating smaller fractional $S$, more $R$, and more SS; and CAM showing appreciably greater $S$, negative $R$ (indicating net evaporation below the melting layer), a much larger percentage of $W$ and much less SS. Possible reasons for the wide differences between the satellite- and model-based results are discussed.
\end{abstract}

\section{Introduction}

The phase of clouds and precipitation, whether it be liquid and/or ice, has far-reaching implications for

Supplemental information related to this paper is available at the Journals Online website: https://doi.org/10.1175/JAS-D-190352.s1.

Corresponding author: Andrew Heymsfield, heyms1@ucar.edu
Earth's energy budget, convective instability, and surface water supply. Major recent advances in understanding the energy budget, and the occurrence of the ice phase, have been provided by satellite data and globally gridded reanalyses (e.g., Trenberth et al. 2001; Trenberth and Stepaniak 2003a,b; Mülmenstädt et al. 2015). It is well known that the ice phase has a major impact on the thermal equilibrium of the planet in terms of how it affects Earth's radiation budget and its effect on the dynamics of convection due to the release of ice 
latent heat upon condensation and loss of heat due to melting of ice (Matus and L'Ecuyer 2017). The focus of our study is on the impact and prevalence of the ice phase to the global distribution of surface precipitation, be it in the form of rain that has some component of melted ice/snow/graupel, rain with no contribution from the ice phase, or snow that falls to the surface.

Most satellite-based retrievals of precipitation have focused on the total precipitation at the surface, not partitioning by the phase. Adler et al. (2017) examined global surface precipitation over a 23-yr period, using the Global Precipitation Climatology Project (GPCP). The monthly precipitation data from the GPCP product are obtained by merging a variety of data sources, including passive microwave-based rainfall retrievals, infrared rainfall estimates, and surface rain gauges. They reported on key features of the global and latitudinally averaged distribution of global mean precipitation, yielding an estimated mean precipitation rate (PR) globally of $2.6 \mathrm{~mm} \mathrm{day}^{-1}$ ( $2.8 \mathrm{~mm} \mathrm{day}^{-1}$ for oceans, $2.1 \mathrm{~mm} \mathrm{day}^{-1}$ for land). Updating that work by using 36 years of GPCP data, they found that the global precipitation value has shown no significant upward trend over the 23-yr period, an unexpected result given that has been explained as resulting from the dual influences of green has warming and aerosol cooling (Salzmann 2016). More recently, SkofronickJackson et al. (2019) used 1 year of GPM-based PR retrievals, derived from both active and passive satellite data, to examine the latitudinally averaged global mean daily precipitation and the annual mean accumulated precipitation. These were compared to the GPCP products. Overall, there was good agreement between GPCP and retrievals from measurements for 1) the GPM Ku-band radar, 2) the GPM dual-wavelength measurements, and 3) the GPM passive microwave precipitation (GPROF) product. They also used 1 year of GPM Microwave Imager (GMI) data, which does have the ability to sense light rain and falling snow, to characterize the average fraction of precipitation that fell as snow and the average snow rate. Although they cautioned that the results were not validated, they found that on average, the snow rates were $<1 \mathrm{~mm} \mathrm{~h}^{-1}$, except at coastal areas, and the fraction of snow events showed a clear latitudinal dependence, with nearly $100 \%$ frequency of annual occurrence above a latitude of $+55^{\circ}$. It is important to point out, however, that there can be substantial disagreement between the precipitation products used. Sun et al. (2018) concluded that there are substantial disagreements between 30 global surface precipitation datasets, depending upon whether they were derived from surface rain gauges, satellite-based, or reanalysis products. They noted that the reliability of precipitation datasets is mainly limited by the number and spatial coverage of surface stations, the satellite algorithms, and the data assimilation models.

The CloudSat Cloud Profiling Radar (CPR) is better suited for measuring light snow precipitation than that of GPM. Liu (2008) used 1 year of CPR data to characterize the global horizontal and vertical distributions of surface snowfall rates. He found that there is an almost zonally oriented high snowfall belt centered around $-60^{\circ}$ latitude, where both surface snowfall frequency and rate are high, whereas in the Northern Hemisphere, heavy/frequent snowfall areas are locked to geographical locations (e.g., coast regions near the Gulf of Alaska). He also found that the zonally and annually averaged snowfall rate has its maximum value around $2 \mathrm{~mm} \mathrm{day}^{-1}$, about one-third of the zonally averaged rainfall value found in the intertropical convergence zone, which signified the importance of snowfall to the hydrological cycle.

Collocated multiple radar datasets have been developed for the purpose of understanding the strengths and limitations of each dataset. Turk (2016), Yin et al. (2017), and Casella et al. (2017) reported on coincident datasets that provide examples of snowfall events observed by the CPR and Dual-Frequency Precipitation Radar (DPR). Using the Turk (2016) dataset, Casella et al. (2017) found that the occurrence of snowfall events correctly detected by DPR products was quite small compared to CPR (around 5\%-7\%), and the fraction of snowfall mass was not negligible (29\%-34\%). Yin et al. (2017) also matched CPR and DPR positions to yield a coincident dataset. The primary focus of that study was to characterize W-, Ka-, and Ku-band radar reflectivity signatures of the ice particles in stratiform versus convective clouds over ocean. Using calculations for snow aggregates, they found clear differences in the triple-wavelength signatures in convective versus stratiform clouds. Sindhu and Bhat (2013) compared radar reflectivity measurements from CPR and the Tropical Rainfall Measuring Mission (TRMM) Ku-band precipitation radar for coincident passes of the CloudSat and TRMM platforms. Above the TRMM radar detection threshold of about $17 \mathrm{~dB} Z$, they found that CPR underestimated the radar reflectivity by about $10 \mathrm{dBZ}$. They explained the difference to be the result of strong attenuation in precipitating clouds. In Behrangi et al. (2012), a merged CPR and TRMM Precipitation Radar database, along with passive remote sensors, was constructed for the purpose of capturing rain rates spanning a wide range of rain intensities. They found that less than $5 \%$ of the rain events were underestimated by CPR owing to the problem of signal saturation in the heaviest rainfall. Behrangi et al. (2014) compared rainfall rates derived from CPR and the TRMM radar, with the addition of passive remote sensors. They found 
that about one-half of the precipitation events are measured by TRMM radar when compared to CPR.

Combining radar data acquired at multiple wavelengths to determine precipitation rates is not straightforward. The assumptions used for developing the algorithms to retrieve these rates are different for CPR and GPM/TRMM, the attenuation differs, as does their footprint sensing areas. Skofronik-Jackson et al. (2019) found that even when accounting for differences in profile classification (snow versus rain), footprint size, and sensitivity, there remains a difference of $30 \%-40 \%$ in global mean snowfall rate between the CPR and GPM Ku-/Ka-band DPR estimates. They found that the mean global snowfall rate between $-66^{\circ}$ and $+66^{\circ}$ latitude was $0.12 \mathrm{~mm} \mathrm{day}^{-1}$ for CPR and about $0.04 \mathrm{~mm} \mathrm{day}^{-1}$ for DPR. They developed a composite CloudSat-GPM $Z-S$ relationship to minimize the algorithm differences. The CPR-DPR snowfall amount differences were reduced to $\sim 16 \%$ after adopting this diagnostic $Z-S$ approach.

Quantifying changes in snowfall as a result of global warming has recently been receiving attention, in part because of the societal impact. Snow is a much more efficient water resource than rain. As the climate warms, a lower proportion of winter precipitation falls as snow (see Tamang et al. 2019, among others), and, as Barnett et al. (2005) have pointed out, one-sixth of Earth's population relies on glaciers and seasonal snowpack for their water supply. Brown and Robinson (2011) have shown that the extent of snow cover in the Northern Hemisphere has undergone significant reductions over the past 90 years, with the rate of decrease accelerating over the past 40 years. In mountainous regions, the snowfall has been decreasing (Howat and Tulaczyk 2005; Knowles et al. 2006; Feng and $\mathrm{Hu}$ 2007; Valt and Paola 2013; Gusain et al. 2014; Guo and Li 2015; Wang et al. 2016). Tamang et al. (2019) used the surface dewpoint temperature of $1^{\circ} \mathrm{C}$ to delineate snow from rain, together with many surface observation reanalysis datasets, to document changes in global snowfall over the past 40 years. They found that over mountainous regions there has been a significant decrease in the annual mean areas of potential snowfall dominant regions. They also found that the Northern Hemisphere rain-tosnowfall transition latitudes were contracting significantly. For current and future climate scenarios, it is important to gain a baseline of the fraction of Earth's precipitation that is due to the ice phase and the fraction due to warm rain involving no ice.

While it seems counterintuitive to associate precipitation in the tropics with the ice phase, several studies have shown that this pathway can be significant. Behrangi et al. (2014) used 3 years of CPR data to derive the global distribution of total precipitation, rain only (but there may be ice aloft), snowfall, and both snow and rain at the surface. They found that snow is the dominant type of precipitation poleward of $\pm 50^{\circ}$ latitude over land; they also concluded that nearly $50 \%$ of global precipitation occurs in the form of snow, but that less than $50 \%$ of global precipitation is captured by the current suite of precipitation measuring sensors. Mülmenstädt et al. (2015) reported on the use of CloudSat radar and CALIPSO lidar data to produce global climatologies of precipitation frequency according to its thermodynamic phase, whether solely through the liquid phase (warm rain), from snow aloft that melted to rain (cold rain), or solely due to the ice phase (snow). They found that the warm rain fraction was highest in the tropical and subtropical oceans outside of the ITCZ, and cold rain dominated in the ITCZ over the midlatitude oceans and over continents. Field and Heymsfield (2015) followed up that study. Using CPR data, they identified four precipitation flags: (0) for no precipitation, (1) for snow at the surface, (2) for rain at the surface, and (3) for rain at the surface contiguous with snow aloft in the same vertical column, that is, rain from melting snow. They compared their results to simulations using a global climate model and surface-based measurements at two ground sites, and to the findings from the Mülmenstädt et al. (2015) study. The correspondence between the CPR observations and the model and ground-based observations was favorable. It was concluded that the CPR observations are a good way to assess the microphysical processes incorporated in the global models. Although the results were generally in agreement with the Mülmenstädt et al. (2015) study, differences in the interpreted occurrence of warm rain over land, and a lower occurrence of precipitation over the Rocky Mountains, were noted. As we will show, CPR is good for the detection of precipitation, but quantification of the amount of precipitation is an issue due to attenuation of the radar beam and non-Rayleigh ice scattering effects at its radar wavelength.

Our study takes the Behrangi et al. (2014), Mülmenstädt et al. (2015), and the Field and Heymsfield (2015) studies one step further by deriving the global distribution of the fraction of surface precipitation that is a result of ice phase processes. This is a multipronged approach that uses a combination of satellite-based data and global climate model output in the investigation. Section 2 describes the methodology and section 3 presents the results. Section 4 summarizes the results.

\section{Data}

Satellite-based data from the W-band CloudSat CPR and the Ku-band radar on the GPM mission are used in 
TABLE 1. Data sources for snow rate $(S)$, rain rate $(R)$, where $S_{\mathrm{MLT}}$ is the snow at the top of the melting layer, $R_{\mathrm{MLB}}$ is the rain at the base of the melting layer, and $R_{\mathrm{SFC}}$ is the rain at the surface.

\begin{tabular}{lcccc}
\hline \hline \multicolumn{1}{c}{ Data source } & $S_{\mathrm{MLT}}$ & $R_{\mathrm{MLB}}$ & $R_{\mathrm{SFC}}$ & Attenuation \\
\hline CloudSat snow product & $\mathrm{Y}$ & - & - & $\begin{array}{c}\text { Significant in regions of supercooled } \\
\text { liquid water } \\
\text { CloudSat } \text { rain product }\end{array}$ \\
GPM Ku band & $\mathrm{N}$ & $\mathrm{Y}$ & Y over ocean & Significant \\
GPM GMI (GPROF) & $\mathrm{Y}$ & $\mathrm{Y}$ & $\mathrm{Y}$ & Generally small \\
TRMM & $\mathrm{N}$ & $\mathrm{N}$ & $\mathrm{Y}$ & - \\
CAM & $\mathrm{Y}$ & $\mathrm{Y}$ & $\mathrm{Y}$ & - \\
Met Office Unified Model & $\mathrm{Y}$ & $\mathrm{N}$ & $\mathrm{Y}$ & - \\
GPCP & $\mathrm{Y}$ & $\mathrm{Y}$ & $\mathrm{Y}$ & - \\
\hline
\end{tabular}

this study. These data, which are infrequently collocated, are composited using the methods described later in this section. The GPM Ka-band data and the combined GPM Ka- and Ku-band data are not used because 1) the Ku-band product has a much larger sample size than the Ka-band data and we are not confident that the combined data are superior to the Ku-band data because of the extra assumptions/uncertainties used for the correction of attenuation and multiple scattering in the current version 6 products. Although algorithms have been developed to classify cloud types (CloudSat; Sassen and Wang 2008; TRMM/GPM; Houze et al. 2015), we have not opted to classify the satellite-based precipitation components into stratiform and convective components. For comparison purposes only, because it does not cover the latitudinal range we need, we use data from the TRMM as well. Climate model output from the NCAR Community Atmosphere Model (CAM) and the Met Office Unified Model (UM) provide detailed surface precipitation type and rates and precipitation rate at the melting level. As a constraint on global precipitation, data from GPCP are used. Table 1 summarizes some of the details of the data sources used in this study.

\section{a. CloudSat cloud profiling radar}

The CPR is a nadir-looking radar that measures the backscattered power from cloud and precipitation at $94 \mathrm{GHz}$. Its minimum detectable reflectivity is about $-30 \mathrm{dBZ}$. The horizontal spatial resolution is about $1.4 \mathrm{~km}$ across the track and $2.3 \mathrm{~km}$ along the track. A single CPR reflectivity profile contains a total of 150 bins with a vertical bin size of about $240 \mathrm{~m}$.

The CPR snow profile product (2C-SNOW-PROFILE) provides estimates of vertical profiles of snowfall rate for radar reflectivity profiles observed by the CPR. For the CPR analysis, the 2C-PRECIP-COLUMN product (Haynes et al. 2009, 2011), version P1_R04, accounts for attenuation and multiple scattering of the radar beam and precipitation identification in the groundclutter region, assumed to be the lowest five radar bins above the surface, approximately $1.2 \mathrm{~km}$ (Marchand et al. 2008). The 2C-PRECIP-COLUMN product is restricted to rain that reaches the surface. It flags precipitation as "rain possible," "rain probable," and "rain certain," while it excludes frozen or mixed-phase precipitation. The 2C-RAIN-PROFILE (Lebsock and L'Ecuyer 2011) product is derived only over ocean because it relies on a radar return from a surface with known radar backscatter cross section. The method will not work if the radar beam is completely attenuated. Data from 2007 to 2010 were used, after which daylightonly operations began because of a battery malfunction. Although the diurnal cycle is not accounted for directly in the CloudSat 2C-RAIN-PROFILE data we used, because the data are collected over the ocean, the cycle should not pose a problem.

\section{b. GPM and TRMM}

In our study, we only use the GPM Ku-band radar measurements (2015-16) and not the Ka-band or dualwavelength radar analysis because the Ku-band radar has a wider swath and attenuation is much less significant than that of the Ka-band radar measurements. The minimum detectable reflectivity is about $13 \mathrm{~dB} Z$. The method for determining rain and snow precipitation from GPM is based on Seto et al. (2013). The particle size distribution (PSD) functional form is derived from a normalized gamma-type PSD model. An optimization approach is used where a relationship is developed between rain rate and mass-weighted diameter. This is an evolution of the approach developed by Iguchi et al. (2009).

We have examined 18 years of GPROF retrievals from the TRMM. They are only used for comparison with the data from CPR/GPM because the latitudinal range covered by $\mathrm{TRMM},-35^{\circ}$ to $+35^{\circ}$, does not cover the important range of latitudes needed for this study. Also note that GPROF values below $0.1 \mathrm{~mm} \mathrm{~h}^{-1}$ may not be reliable. Furthermore, GPROF separation of surface snow from rain can be in error 
because 6-hourly reanalysis data are used to derive the surface air temperature.

\section{c. CPR-GPM-TRMM comparison}

A coincident dataset, 2B-CSAT-GPM (Turk 2017), is examined in this study (appendix A). This dataset provides the collocated GMI brightness temperatures and CPR reflectivities, as well as ECMWF ancillary atmospheric fields interpolated to the CPR bin locations. In this dataset, a CPR reflectivity profile is matched to the nearest GMI pixel when two satellite tracks coincide within $15 \mathrm{~min}$. Several other parameters distributed from the CPR and GPM products are also used, such as the CPR cloud masks and snow water content as well as the retrieved GMI cloud ice and liquid water paths. The spatial coverage of datasets is $-65^{\circ}$ to $+65^{\circ}$; the period covers March 2014 to December 2016.

In appendix A we use this dataset to compare measurements from CPR and GPM coincidences. It is shown that $\mathrm{CPR}$ reflectivity (W band) measurements are considerably below those of GPM Ka- and Ku-band reflectivities. This suggests that in these instances, not surprisingly, attenuation at $\mathrm{W}$ band is significant. It is also noted that at CPR reflectivities $>10 \mathrm{dBZ}$ and Ka-band reflectivities of $>25 \mathrm{~dB} Z$, the relative difference between CPR and GPM Ka-band radar data increases. This increase is suggestive of strong nonRayleigh effects and is consistent with the CPR profiles of "dim bands" (Heymsfield et al. 2008).

\section{d. Other radar retrieval considerations}

The CPR is limited in that liquid precipitation is difficult to determine over land. The standard liquid precipitation products use path-integrated attenuation, which requires good information about the surface reflection, as noted above. To overcome this shortcoming, we used the reflectivity to rainfall-rate relationship from Heymsfield et al. (2018, hereafter H18) to retrieve rainfall rate directly from reflectivity. This leads to obvious underestimations due to attenuation of the radar beam. To mitigate the effects of attenuation, we used the Turk (2017) collocation dataset and compared GPM retrieved rainfall rates with the CPR values calculated using H18. As anticipated, when there was little liquid water in the column (i.e., little attenuation), the GPM and CPR H18 values were in reasonable agreement. Lower in a water cloud, the values diverged in a predictable manner. In this way we were able to relate the impact of liquid water attenuation on rainfall rate as follows. First, all CPR reflectivity values in the column were increased by $25 \mathrm{dBZ}$ when reflectivities were above the noise level; this was done to assure nonnegative values. Then, these values were summed in the column above the point of interest within the liquid region. The summed values are a good indication of the liquid water above the point of interest and thus are related to the attenuation of the beam due to liquid water. The summed values were then compared to the ratio of the rainfall rates derived for GPM as compared to those determined with the CPR H18 relationship. It was found using the collocated data that the highest accumulated reflectivities in the column led to a reduction of approximately $80 \%$ when comparing the two methods. Thus we adjusted upward the CPR H18 results based on a fit to this relationship $R_{\text {new }}=R_{18} /\left(1-0.00133 \sum \mathrm{dB} Z\right)$ and $\sum \mathrm{dB} Z=$ $(\mathrm{dB} Z+25)$ for all range gates between the gate of interest and the melting level, where $R_{\text {new }}$ is the new rain rate and $R_{18}$ is the rain rate determined using H18 (see Fig. S1 in the online supplemental material).

\section{e. Community Atmosphere Model}

The CAM6 used here is a developmental version of the atmospheric component of the CESM. The code base contains developmental code for CESM2. The model is based on CAM5 (Neale et al. 2010), the atmosphere model for CESM1 (Hurrell et al. 2013). This version includes a new unified moist turbulence parameterization, Cloud Layers Unified by Binormals (CLUBB), developed by Golaz et al. (2002) and Larson et al. (2002) and implemented in CAM by Bogenschutz et al. (2012). The model also contains updated cloud microphysics (MG2) described by Gettelman and Morrison (2015), and mixed phase ice nucleation linked to aerosols originally developed by Hoose et al. (2010) and implemented and improved in CAM by Wang et al. (2014), replacing the empirical relationship of Meyers et al. (1992). Simulations were performed at $0.9^{\circ} \times 1.25^{\circ}$ horizontal resolution, with 32 levels in the vertical using measured sea surface temperatures and boundary conditions from year 1979 to 2014 . The model runs with an interactive land surface model, the Community Land Model, version 5 (CLM5). In the calculations for CAM presented later, a threshold snow precipitation rate of $0.1 \mathrm{~mm} \mathrm{~h}^{-1}$ is used to determine if there is snow flux above the melting layer.

\section{f. Met Office Unified Model}

The Met Office UM was used to generate global precipitation rate data. The UM was run in Climate mode with a midlatitude grid spacing of $125 \mathrm{~km}$; the configuration used was Global Atmosphere 7 (GA7; Walters et al. 2017). Parameterizations represented the cloud fraction (Wilson et al. 2008); large-scale stratiform mixed-phase cloud microphysics (Wilson and Ballard 1999), with changes to the snow PSD representation following (Field et al. 2007); convection (Gregory and Rowntree 1990); 


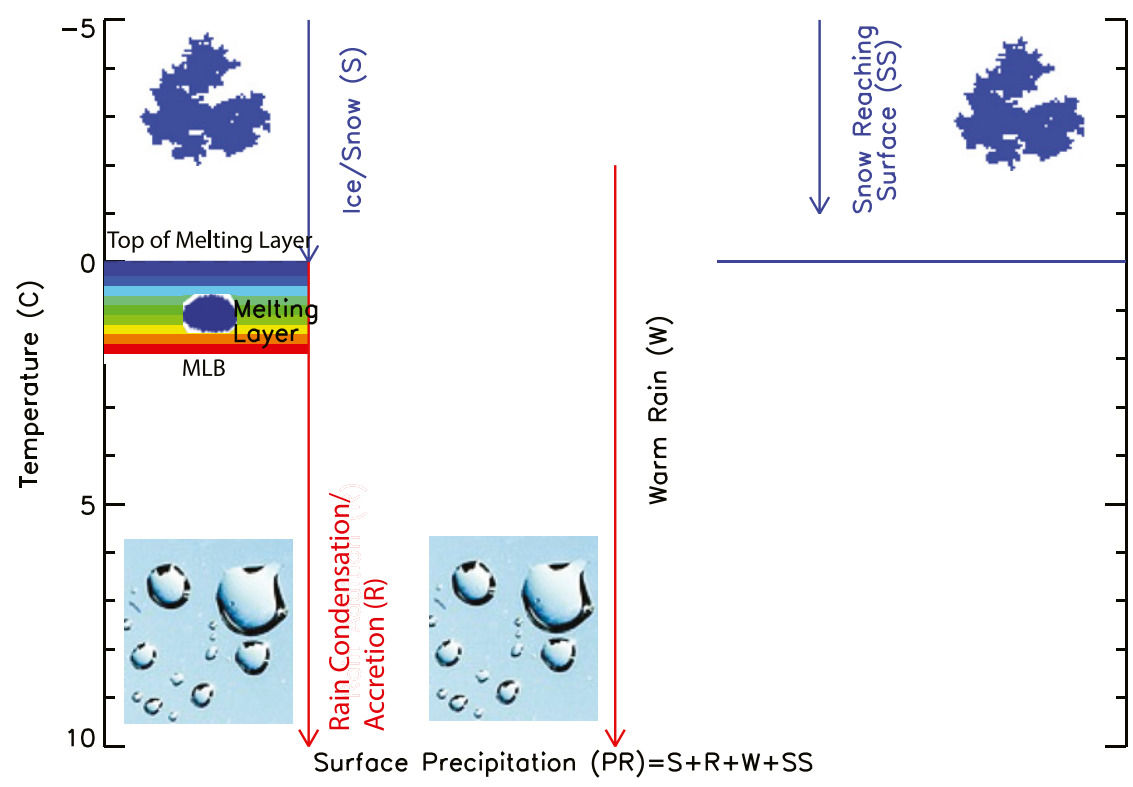

FIG. 1. Schematic showing the different pathways leading to precipitation at the surface.

and boundary layer mixing (Lock et al. 2000). The convection parameterization has a simple microphysical representation. For this analysis we output the total precipitation rate at the first model level above $0^{\circ} \mathrm{C}$ (for surface precipitation exceeding $1 \mathrm{~mm} \mathrm{day}^{-1}$ ) and rain and snow rates at the surface. We determined if the rain at the surface came from melting snow or was warm rain only. The model was run for 10 years (1989-98 inclusive), and the first 3 months were discarded as spinup.

\section{Results}

\section{a. Data synthesis}

This section examines the global distribution of snow rates and rain rates, both aloft and at the surface, using the data discussed in section 2, with the goal of estimating the separate contributions of the pathways of 1 ) snow and ice that forms above the freezing level and melts to produce rain $(S)$, which can be added to by an additional component: condensation and collection as the melted ice/snow as it falls to the surface $(R), 2$ ) liquid phase only coalescence, warm rain $(W)$, and 3 ) snow that falls to the surface (SS) to the global mean precipitation rate $(\mathrm{PR})$. Note that a drop that falls to the surface, having followed pathway $S$, has a mass (and therefore precipitation rate) that is the sum of $S+R$. Furthermore, the component $R$ can be negative if there is evaporation of the drop below the melting layer.

Figure 1 shows a schematic of the contributions of the liquid and ice phases to surface precipitation. All results are weighted by the cosine of the latitude used to account for the convergence of the meridians toward higher latitudes, thereby lessening the impact of high-latitude grid points that represent a small area of the globe.

The leftmost contribution in the figure is due to a combination of precipitating ice (ice crystals, snow, graupel, and hail) falling into the melting layer $(S)$, which we take as the value of PR at the base of the melting layer (MLB), and condensation and collection of water as the melted ice/snow falls to the surface plus any contribution from the liquid phase only $(R)$. The MLB is considered to yield a more accurate estimate of the snow rate falling into the melting layer (ML) for the radar retrievals because there is less uncertainty about the backscatter cross sections and mass-dimensional relationship for rain (MLB) than for snow (top of ML). Note that an adjustment does not have to be made for the decrease in the $S$ as particles fall from a pressure level $P$ to the surface pressure assumed to be $1000 \mathrm{hPa}$, because the snow flux should be relatively constant (concentration increases as the terminal velocity decreases), unless there is evaporation below the melting layer.

The middle contributor is warm rain $(W)$, which involves the liquid phase only. Note that rain produced above the melting layer in combination with snow above the melting layer that falls through the melting layer is not considered as its contribution is likely to be relatively small. Although the AMS Glossary of Meteorology defines warm rain as rain formed from a cloud having temperatures at all levels above $0^{\circ} \mathrm{C}$ and resulting from the droplet coalescence process, we broaden the 


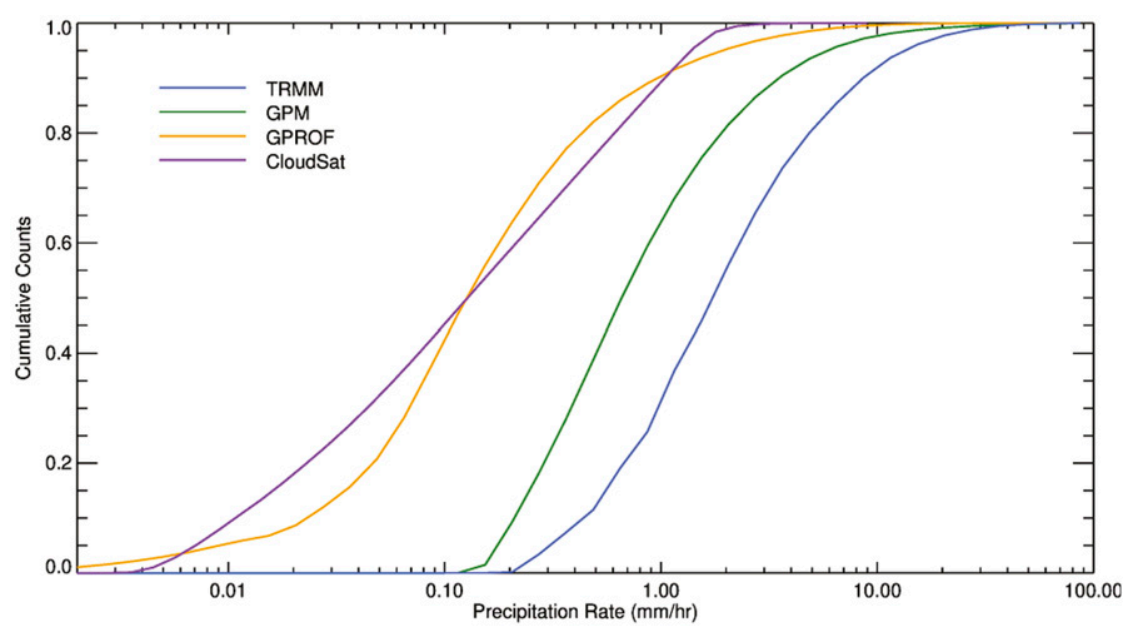

FIG. 2. Cumulative PDF of surface precipitation rate for events where there is snow in the vertical column. These are shown for CloudSat (CPR), GPM, GPROF, and TRMM. This figure is meant to show the ranges of the detection of precipitation rate by the different sensors. Note that GPROF values below $0.1 \mathrm{~mm} \mathrm{~h}^{-1}$ are of questionable accuracy.

definition of warm rain to include all temperatures where the ice phase is not involved in the precipitation process. Therefore, although warm rain can be topped any height in our analysis, it is arbitrarily taken to be the $-2^{\circ} \mathrm{C}$ level in the figure.

Last, on the right is snow that reaches the surface (SS). Skofronick-Jackson et al. (2019) show the global distribution of total annual amounts of surface snowfall using data from active and passive remote sensors averaged for several annual cycles. Here, we look at the snowfall rates.

Given that the present analysis uses data from spaceborne radars that have different wavelengths and detection capabilities, it is useful to examine the range of snow precipitation rates that can be detected by the various satellite-based measurements. In Fig. 2, PDFs of the satellite-based precipitation rate products are plotted as a function of the precipitation rate. The peak in the PDFs for the active remote sensors fall in the range from about 0.2 to $2 \mathrm{~mm} \mathrm{~h}^{-1}$. The CPR has a much lower PR detection threshold than GPM and TRMM but does not extend to same upper limit. The distributions for the land and ocean areas are roughly comparable for each sensor. The GPROF product peaks at about an order of magnitude lower than the active remote sensors. Values below $0.1 \mathrm{~mm} \mathrm{~h}^{-1}$, however, although reported for GPROF, may not be accurate; therefore, the GPROF peak PDF values are likely to be higher than shown.

It is useful to compare the latitudinal distribution of $\mathrm{PR}$ as derived from the active satellite remote sensors to the GPCP (surface) product. Note that, although GPCP data are available at $3 \mathrm{~h}$ intervals, we average all the data at each location such that the diurnal cycle should not be a factor in the comparisons later. For the former, we use the CPR data to a maximum reflectivity of $8 \mathrm{dBZ}$ combined with the GPM data at higher values. The $8 \mathrm{~dB} Z$ cutoff was suggested by Skofronick-Jackson et al. (2019), and in appendix B we show that the $8 \mathrm{~dB} Z$ cutoff is reasonable. The agreement between the GPCP product and the combined CPR-GPM data is excellent, with the exception of the region from about $-30^{\circ}$ to $-60^{\circ}$ (Fig. 3). It is unclear what this difference is due to and further investigation is warranted. Also shown in the figure are CPR cutoff reflectivities of 10,12 , and $14 \mathrm{dBZ}$. These add considerable average rain rates to the midlatitudes but worsen the agreement with the GPCP mean PR.

The latitudinal distributions of the mean PR as derived from the model and satellite-based data are shown in Fig. 4. In the latitude range $-35^{\circ}$ to $+35^{\circ}$, all PR except the CPR product is either close to or somewhat higher than the GPCP product. This low bias is presumably due to attenuation of the radar signal in the high-reflectivity convective regions, which the retrieval product evidently does not capture. Because we only use the CPR products for reflectivities $8 \mathrm{dBZ}$ and below, with the correction above for $R_{\text {new }}$ combined with the GPM product at higher reflectivities, as suggested by Skofronick-Jackson et al. (2019), the low bias from the CPR retrievals should largely disappear because the GPM PR are significantly higher. Note that because the CPR mean PR shown in the figure could also be in part due to the lower detection threshold relative to the other radar-based retrievals, although this is unlikely because both CAM and the UM also show higher mean PR. The UM product is generally higher than the GPCP product, especially in the tropics, $-23.5^{\circ}$ to $+23.5^{\circ}$, but this may 


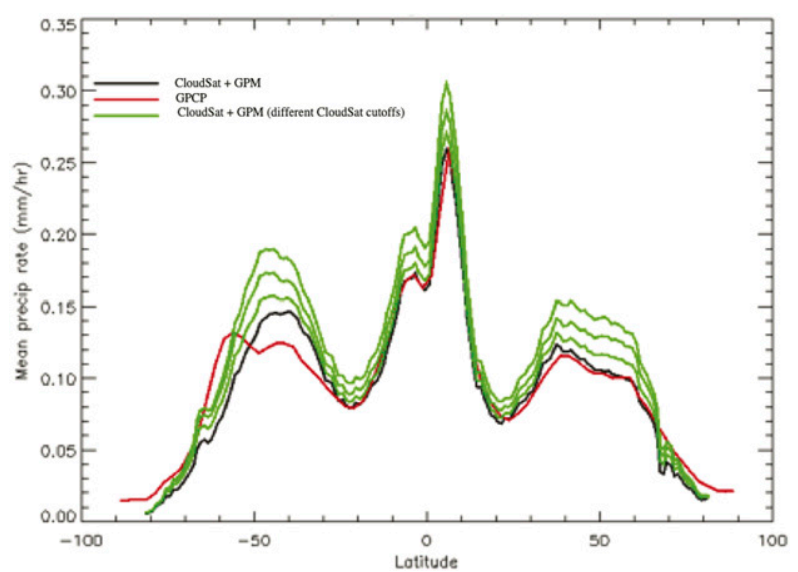

FIG. 3. Comparison of GPCP and CloudSat + GPM surface precipitation products, where CloudSat is restricted to $<8 \mathrm{dBZ}$ and GPM wherever GPM detects surface precipitation. Also shown are CloudSat cutoff reflectivities of 10,12, and $14 \mathrm{dBZ}$.

be partly related to interannual variability (nonoverlapping simulation and observation period). The CAM PR are quite close to the GPCP product.

The results shown in Fig. 4 display some interesting aspects of the latitudinal variations in PR. Distinct peaks are noted about $-10^{\circ}$ and $+10^{\circ}$, a factor related to the ITCZ. An enhanced PR region is noted both in the satellite and model based products in the latitude range $-40^{\circ}$ to $-60^{\circ}$. This is due to heavy precipitation associated with frontal regions in the Southern Ocean (Catto and Pfahl 2013). Relative minimum values occur around $-20^{\circ}$ and $+20^{\circ}$ latitudes.

The global distribution of the latitudinally averaged snow rates (SR) at the top of the ML, and the rain rates
(RR) at the base of the ML and at the surface for all of the data sources, are shown in Fig. 5. Where available, the rain rates at the base of the melting layer are shown. The highest PR are noted for the UM (Fig. 5e), with the somewhat lower peaks noted for the other data sources (Figs. 5a-d). On average, the GPM and TRMM radar values are lower than for the other data sources.

Of interest is the fraction of surface rainfall that is due to warm rain $(W)$. Mülmenstädt et al. (2015) used 5 years of CloudSat CPR/CALIPSO CALIOP data to examine the frequency of occurrence of warm rain. They found that the fraction of clouds that were warm rain was only $1 \%$ over land in the extratropics (poleward of $+30^{\circ}$ ) and $8 \%$ in the tropics, while the warm-rain phase fraction over ocean was $15 \%$ in the extratropics and $44 \%$ in the tropics. Liu and Zipser (2009), using TRMM data, found that warm rain in the latitude range $-20^{\circ}$ to $+20^{\circ}$ contributes about $20 \%$ of the rainfall over tropical oceans and $7.5 \%$ over tropical land. In Fig. 6, we find that in low-latitude regions, the warm rain process accounts for about $40 \%( \pm 20 \%$, dependent on the data source $)$ of the total surface precipitation; Field and Heymsfield (2015), using CPR, found that $66 \%$ of rain events exceeding $1 \mathrm{~mm}$ day $^{-1}$ were warm rain. The combined CPR-GPM source is probably the most accurate, suggesting that the fraction is a peak of order $35 \%$, located at about $-20^{\circ}$ and $+20^{\circ}$ latitudes. In midlatitudes the drop-off in the warm rain process is quite pronounced. There is some warm rain precipitation in the polar regions, presumably due to mostly drizzle-type precipitation. Table 2 shows the regional values calculated from the datasets.

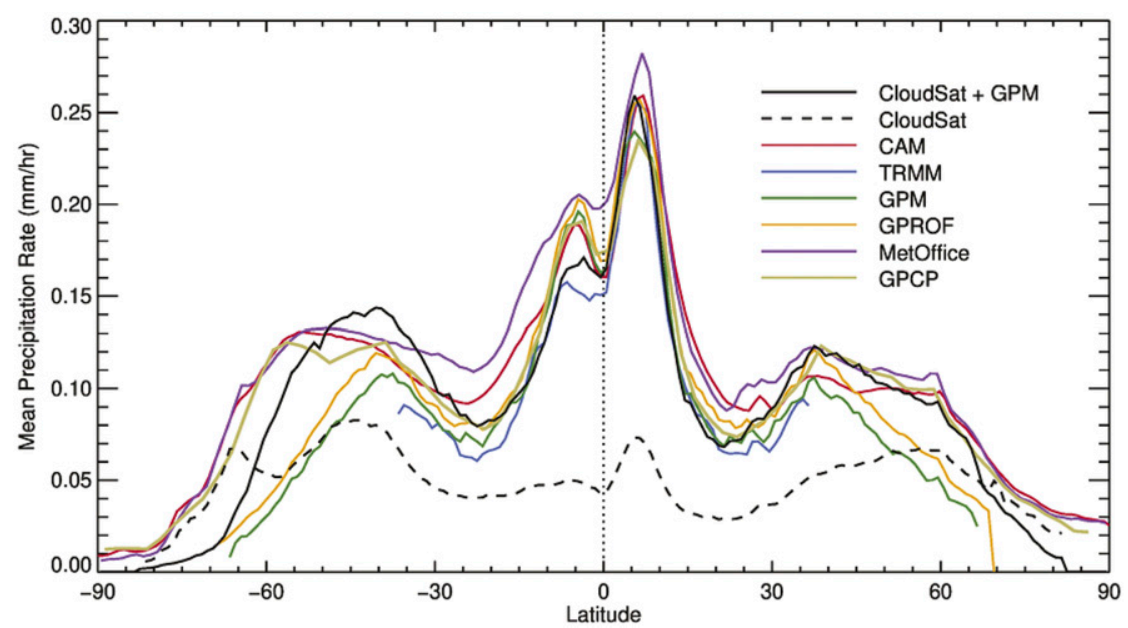

FIG. 4. Mean surface precipitation rate (PR) retrieved from CloudSat, GPM, GPROF, and TRMM, derived from output from CAM and the Met Office models, and from the GPCP product. These are for land and ocean areas. 

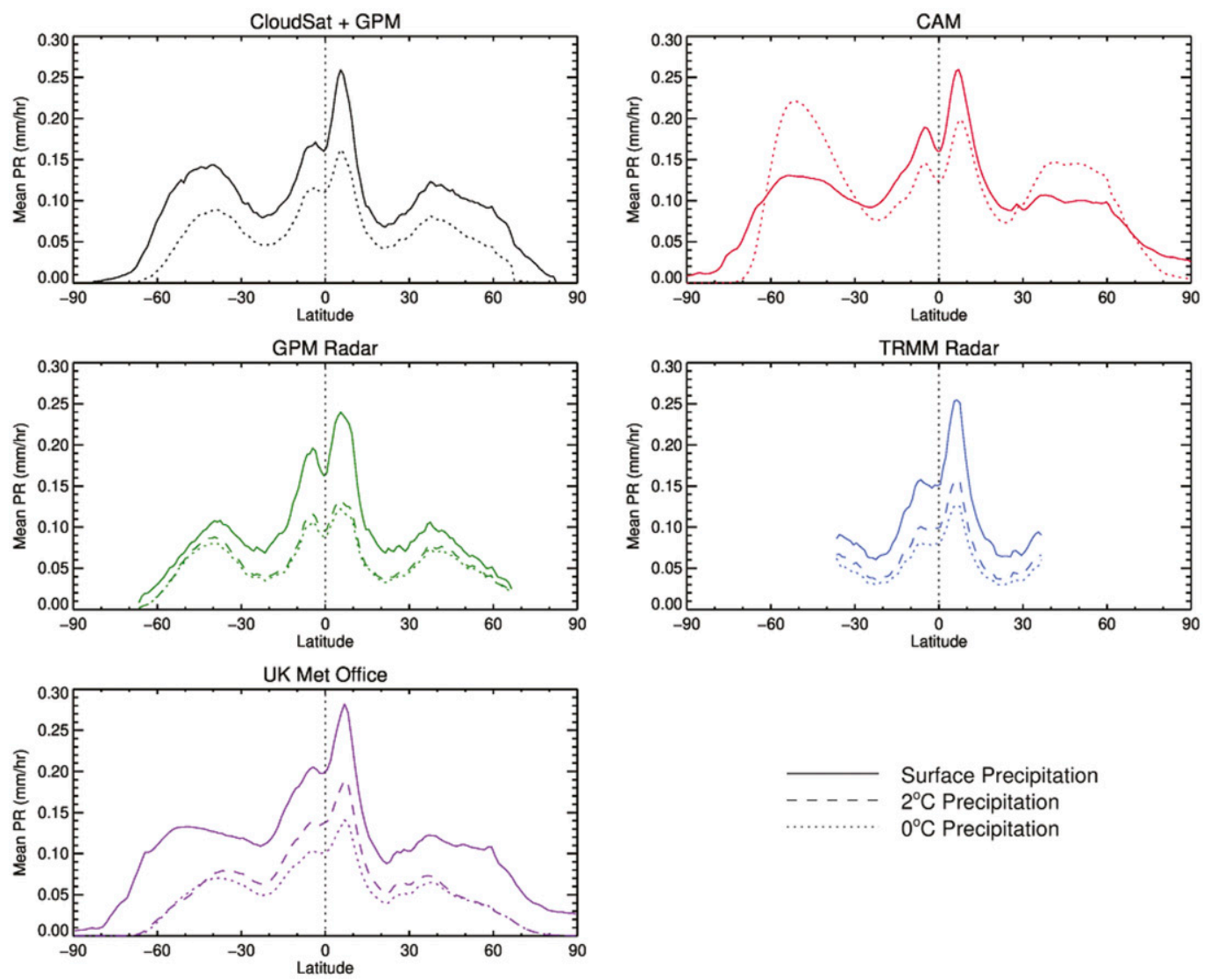

Surface Precipitation

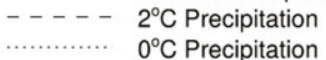

FIG. 5. Latitudinally averaged mean rain rate at the surface and at $2^{\circ} \mathrm{C}$, and, for $0^{\circ} \mathrm{C}$, the snow rate, for all of the data sources except the Met Office model.

We now quantify how each precipitation formation process (Fig. 1) contributes latitudinally to the total surface precipitation. The results for the satellite-based data are shown in Fig. 7. As noted earlier, the latitudinal dependence of the GPCP and the CPR + GPM PR are quantitatively similar (Fig. 7a). The component $S$ closely follows the PR curve, with an average value of about 0.65 (Fig. $7 \mathrm{~b}$ ). The additional water $R$ added to the snow

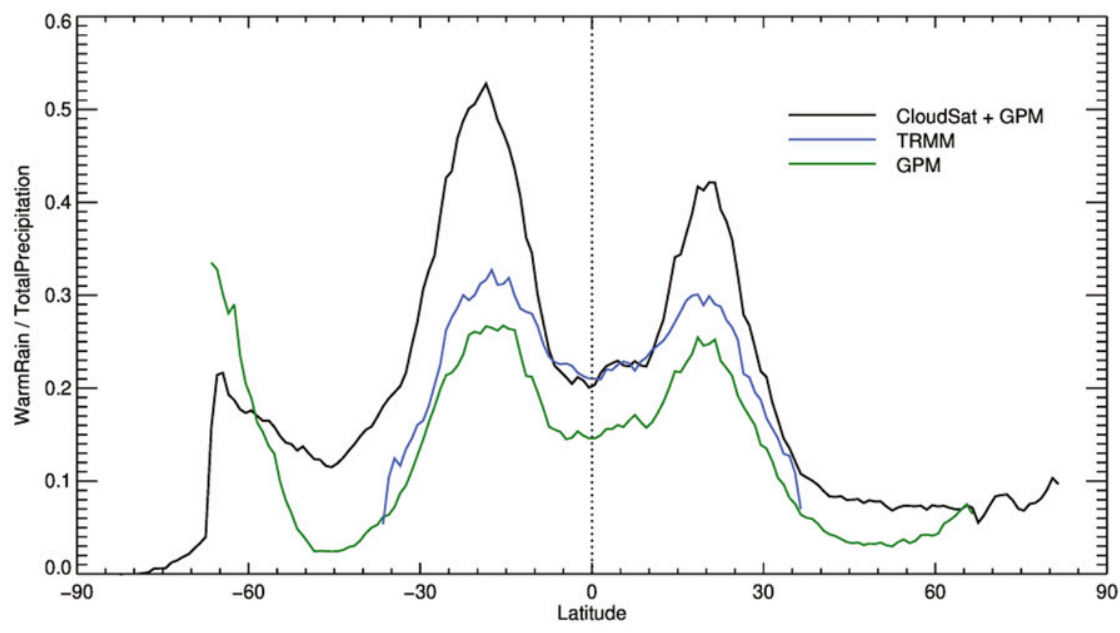

FIG. 6. The fraction of total surface rainfall that is warm rain from CloudSat, GPM, and TRMM. 
TABLE 2. Regional and global total ratios of $S, R, W$, and SS. For each region, values show the fraction of precipitation that arrives at the surface through each pathway. Within each region, the top row is CPR-GPM, the middle row is Met Office UM, and the bottom row is CAM. Regions are as follows: polar regions, poleward from $\pm 66.5^{\circ}$; midlatitudes, $-66.5^{\circ}$ to $-23.5^{\circ}$ and $+23.5^{\circ}$ to $+66.5^{\circ}$; and tropics, $-23.5^{\circ}$ to $+23.5^{\circ}$.

\begin{tabular}{lcccc}
\hline \hline \multicolumn{1}{c}{ Region } & $S$ & $R$ & $W$ & SS \\
\hline North polar & 0.0817 & 0.5070 & 0.0743 & 0.3337 \\
& 0.1638 & 0.1931 & 0.0382 & 0.6048 \\
North midlatitudes & 0.5154 & -0.226 & 0.0 .104 & 0.6067 \\
& 0.5828 & 0.2405 & 0.1194 & 0.0573 \\
North tropical & 0.4289 & 0.3652 & 0.0910 & 0.1147 \\
& 1.1403 & -0.337 & 0.0661 & 0.1306 \\
South tropical & 0.6382 & 0.0963 & 0.2654 & 0.0000 \\
& 0.4595 & 0.4576 & 0.0829 & 0.0000 \\
South midlatitudes & 0.7826 & 0.0191 & 0.1983 & 0.0000 \\
& 0.6335 & 0.0357 & 0.3308 & 0.0000 \\
South polar & 0.4421 & 0.4546 & 0.1032 & 0.0000 \\
& 0.7499 & 0.0081 & 0.2419 & 0.0001 \\
& 0.4000 & 0.2304 & 0.1896 & 0.0665 \\
Global average & 1.1242 & -0.3437 & 0.1037 & 0.1125 \\
& 0.1472 & 0.0280 & 0.0732 & 0.1478 \\
& 0.0059 & 0.0249 & 0.0000 & 0.9130 \\
& 0.0169 & -0.007 & 0.0660 & 0.9427 \\
& 0.5716 & 0.1524 & 0.2271 & 0.0489 \\
& 0.4250 & 0.4112 & 0.0932 & 0.0705 \\
& 0.9189 & -0.152 & 0.1479 & 0.0852 \\
\hline
\end{tabular}

component is significant, with the largest values of $0.4-0.6$ at about $-50^{\circ}$ and $+50^{\circ}$, with a small peak near the equator (Figs. 7a,b). In the subtropics, there are slightly negative values of $R$, indicating net evaporation from the melting layer to the surface. The contribution $W$ to PR not surprisingly increases from high to low latitudes (Fig. 7a), but fractionally shows peaks at about $-20^{\circ}$ and $+20^{\circ}$ (Fig. $7 \mathrm{~b}$ ). The component SS is quite small (Fig. 7a) and increases monotonically at high latitudes $\left(> \pm 50^{\circ}\right)$ (Fig. $7 b$ ).

The results shown for 3 years of the UM are summarized in Fig. 8. It is possible to derive more details from those runs than from the satellite-based results. The enhanced details included separating stratiform and convective precipitation throughout the vertical column, providing $S, R, W$, and SS contributions to the total precipitation, as well as PR and additional warm rain mixed with snow at the melting layer. The locations of the peak PR are similar to those from the satellite observations (Fig. 8a). In tropical regions, convectively generated PR dominates the total PR, and that component decreases poleward. Conversely, stratiform generated $\mathrm{PR}$ has a relative minimum in tropical regions and increases latitudinally outward, dominating in the midlatitudes. Fractionally, $S$ is about $10 \%$ lower than for the satellite observations, and $R$ is
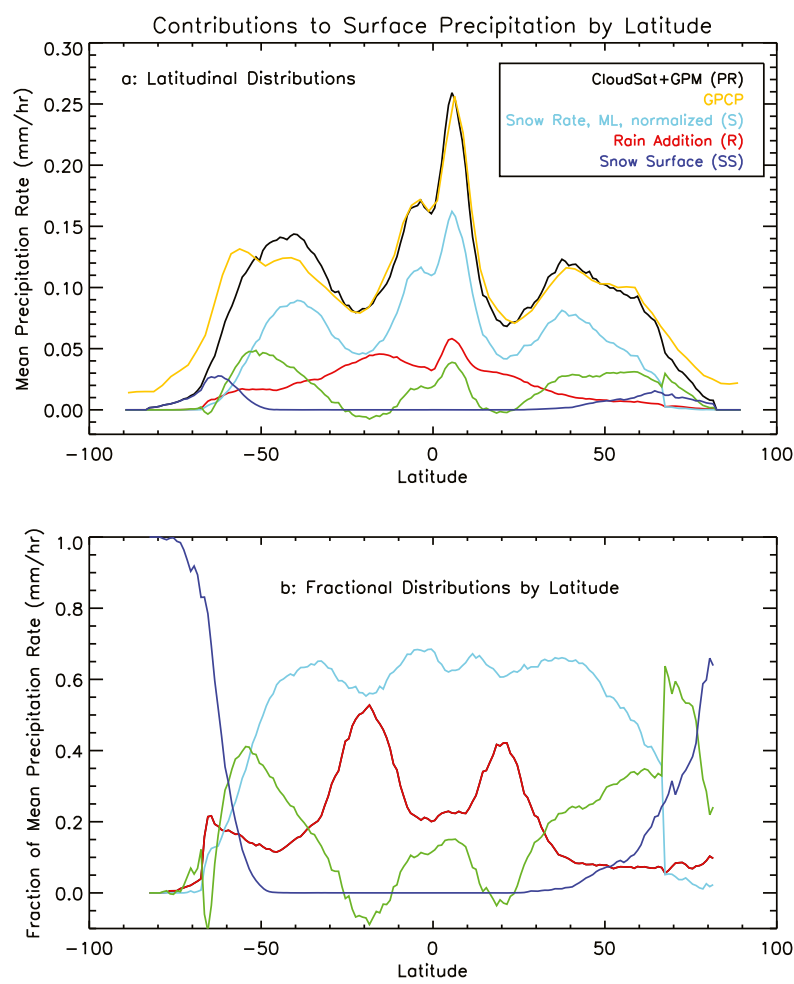

FIG. 7. CloudSat- and GPM-derived latitudinal dependence of the (a) mean precipitation rate and (b) fractional dependence of the contributions to the total surface precipitation rate, classified according to the process involved in its production.

roughly comparable to $S$. The warm rain component $R$ peaks or dominates at about $\pm 20^{\circ}$ latitude, which is similar to the satellite-based findings, but the magnitudes are considerably lower. The components $R$ and $S$ are dominated by convection in tropical regions and decrease outward relative to the stratiform component. The surface snow component SS is about double that for the satellite observations, with the fractional distribution having a similar dependence (Fig. 8b).

The results for the CAM model, divided into convective and stratiform components, also show four primary peaks in $\mathrm{PR}$, at about $\pm 10^{\circ}$ and at $\pm 50^{\circ}$, with a relative minimum between them (Figs. 9a,b). The PR values and distribution are similar to that from the GPCP product. The contribution of $S$ to PR for stratiform precipitation is quite large across a wide range of latitudes, and the fraction exceeds 1.0 at about $+50^{\circ}$ and $-50^{\circ}$ (Fig. 9c). The latter is due to negative values of $R$, indicating significant "evaporation" below the melting layer. The significant evaporation below the melting layer is from stratiform precipitation, which mostly takes place in the midlatitudes, resulting in the pronounced negative $R$ in midlatitudes in both hemispheres. The convective component of $R$ is positive. 

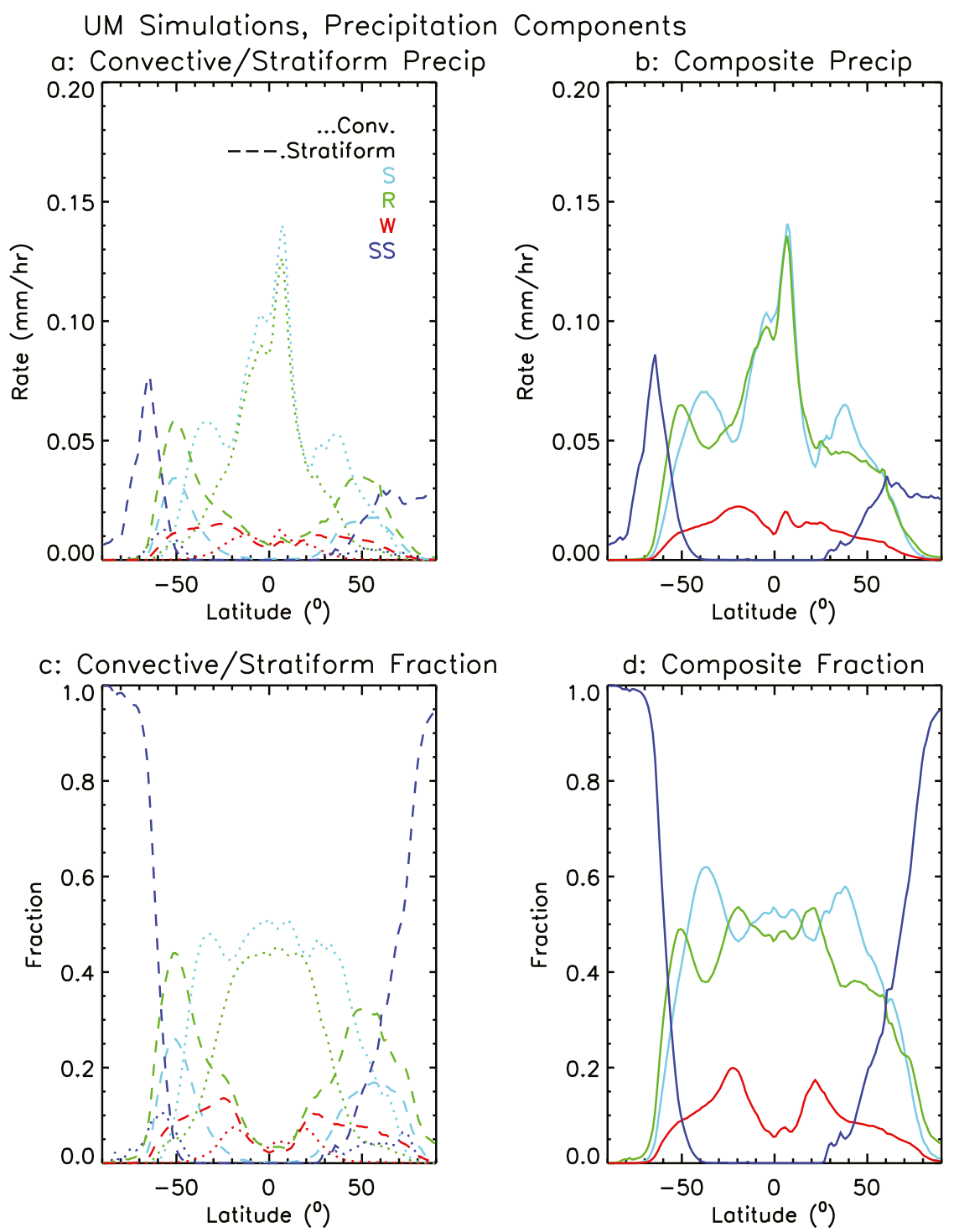

FIG. 8. Latitudinal distribution of the components of surface precipitation from the Met Office climate model runs. (a) Precipitation rates for each precipitation type, subdivided by convective and stratiform-generated precipitation. (b) Total rates for each precipitation type. (c),(d) As in (a) and (b), but for the fraction of total precipitation for each precipitation type.

The distribution of the warm rain component $W$ is considerably larger than for the satellite values with a very different latitudinal distribution (cf. Figs. 7b and 9d). The latitudinal distribution of component SS behaves in an expected manner, except at high polar latitudes, where there is a significant component $W$.

Figure 10 compares the precipitation rate for each of the components as derived from CPR-GPM, UM, and CAM. Note that in each panel of Fig. 10, the color scheme is not the same as that used to represent each of the precipitation components as was done in
Figs. 7-9. Rather, different colors are used to represent each method. For the $S$ component, the satellite-based product and the UM values are quite similar, whereas CAM has considerably higher values in the midlatitudes (Fig. 10a). The latter are offset by sharp negative values of $R$ (Fig. 10b). Values of $R$ for the UM, derived from the sum of the convective and stratiform regions, are relatively high compared to the satellite-based product. The UM values of component $W$ are relatively small compared to the satellite-based product, with CAM indicating high values than UM but lower than the satellite 

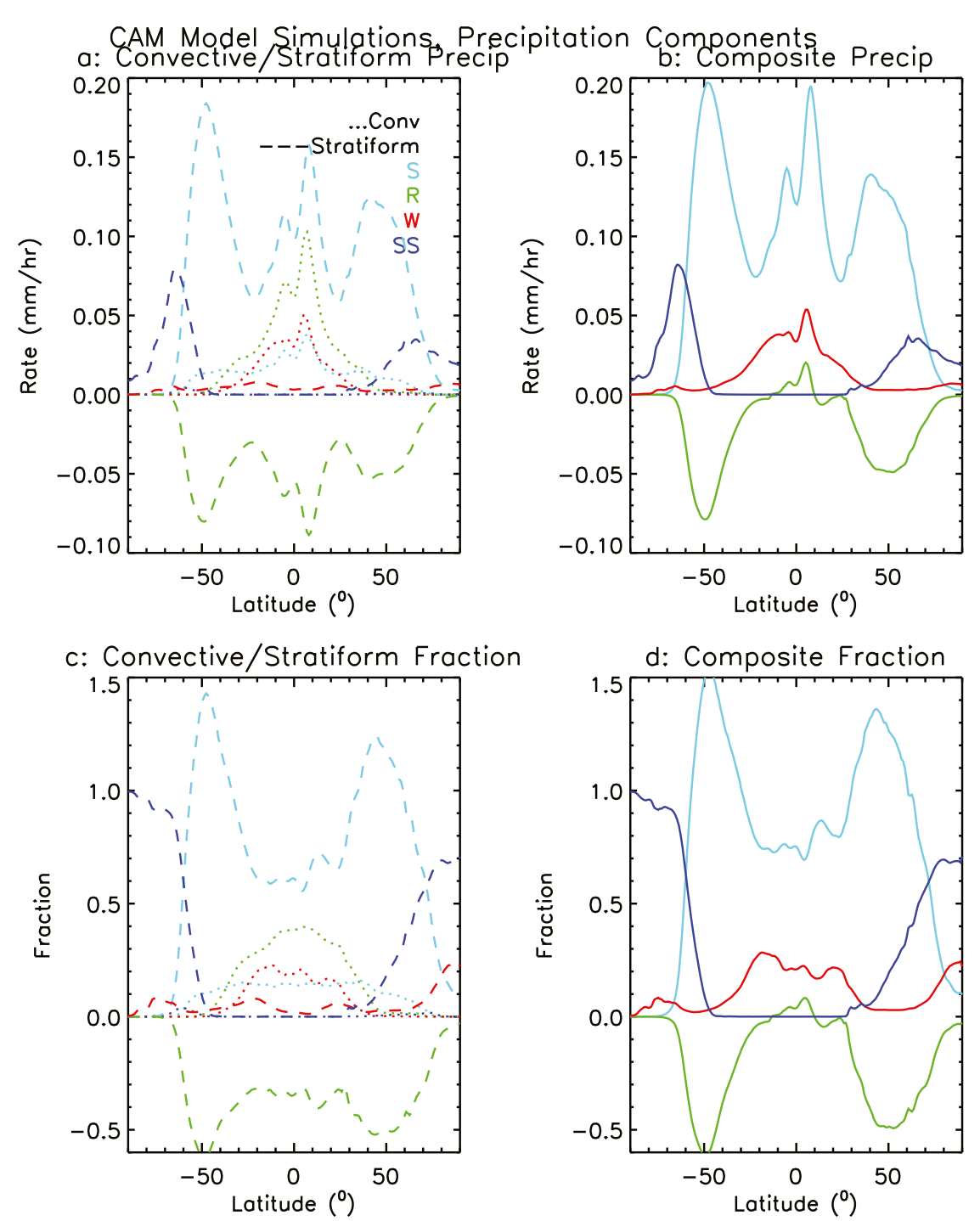

FIG. 9. As in Fig. 8, but for the results from the CAM model runs, partitioning by (a),(c) convective/stratiform and (b),(d) the composite of the two.

$W$ values (Fig. 10c). The UM values of the component SS are similar to those from CAM but considerably higher than the satellite-based values (Fig. 10d).

Figure 11 is similar to Fig. 10, but it compares the fractional components of each of the precipitation type. Relative to the satellite-based products, the fractional component $S$ is about $10 \%$ lower for UM, with a longitudinal distribution that is similar (Fig. 11a). The CAM results are very different, with peaks at about $-50^{\circ}$ and $+50^{\circ}$ latitudes with fractional values exceeding 1.0. From those latitudes to the equator, the CAM values decrease to fractions that are comparable to the satellite-based product. The additional precipitation component from the melting layer to the surface $(R)$ for the UM is roughly comparable to the component
$S$, whereas the satellite-based product shows distinct peaks at around $-50^{\circ}$ and $+70^{\circ}$ latitudes, with relatively little between those peaks (Fig. 11b). These peaks are likely to be due to the fact that at these latitudes, the reflectivities are low and the retrieval is based solely on the CloudSat-only retrievals, which are evidently producing artificially high values of $R$. The CAM product is strongly negative at about the same latitudes as the peaks from the satellite-based product. The warm rain product from the UM shows peaks at latitudes that are about $\pm 20^{\circ}$ as with the satellite-based product, but the former values are about one-half of the latter (Fig. 11c). The CAM warm rain product progressively increases from 0 in the south polar region to about 0.2 at the equator, with a local maximum in the northern polar 
Comparison of Precipitation Rate for Each Precipitation Type
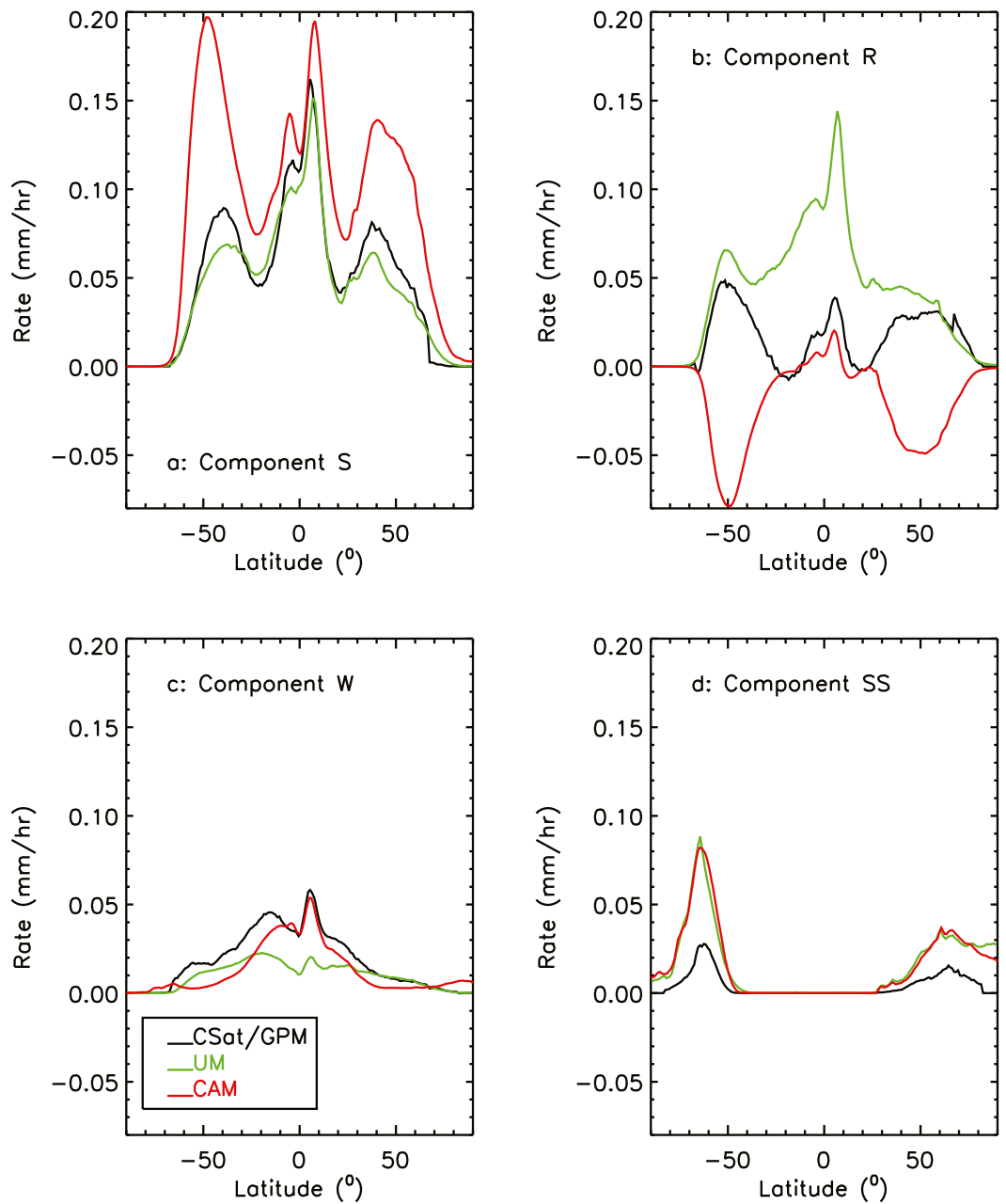

FIG. 10. Precipitation rates for each precipitation type as a function of latitude. (a) Snow that melts to subsequently fall to the ground. (b) The addition of (a) from the melting layer to the surface. (c) Warm rain. (d) Snow that falls to the ground.

region, distinctly different from the other warm rain products. The satellite, UM, and CAM products all show the expected trend of the snow reaching the ground is negligible until latitudes of about $\pm 50^{\circ}$ are reached, monotonically increasing thereafter (Fig. 10d).

The dependence of the various components of PR averaged for the Northern and Southern Hemispheric polar (poleward of $\pm 62.5^{\circ}$ ) and midlatitude $\left(-23.5^{\circ}\right.$ to $-62.5^{\circ}, 23.5^{\circ}$ to $62.5^{\circ}$ ) regions and for the tropical $\left(-23.5^{\circ}\right.$ to $\left.23.5^{\circ}\right)$ regions, and for each of the methods (section 2), are summarized in Fig. 12. For the satellitebased method, the component $S$ is relatively constant throughout the climatic regions, leading to a global average of about 0.595 (Fig. 12a). The component $R$ is highest at high northern latitudes, decreasing monotonically toward the equator, whereas there is a general increase from about $-20^{\circ}$ to the equator, with a global average of 0.51 (Fig. 12b). The trend noted for $W$ is the opposite, increasing monotonically from the polar regions, with a global average of 0.226 (Fig. 12c). The snow reaching the surface SS decreases monotonically from the polar to tropical regions, with a global average of 0.029 (Fig. 12d).

The global distribution of the fraction of precipitation that is due to the ice phase using the satellite and modelbased data is summarized in Fig. 13. For $S$, the satellitebased product is approximately between the global climate model values. Likewise, for $R$, it falls between the model values. What is unexpected is the large negative value for the CAM results, strongly suggesting significant evaporation of condensate below the melting layer. The $W$ for the satellite-based product is 


\section{Comparison of the Fraction of Each Precipitation Type}
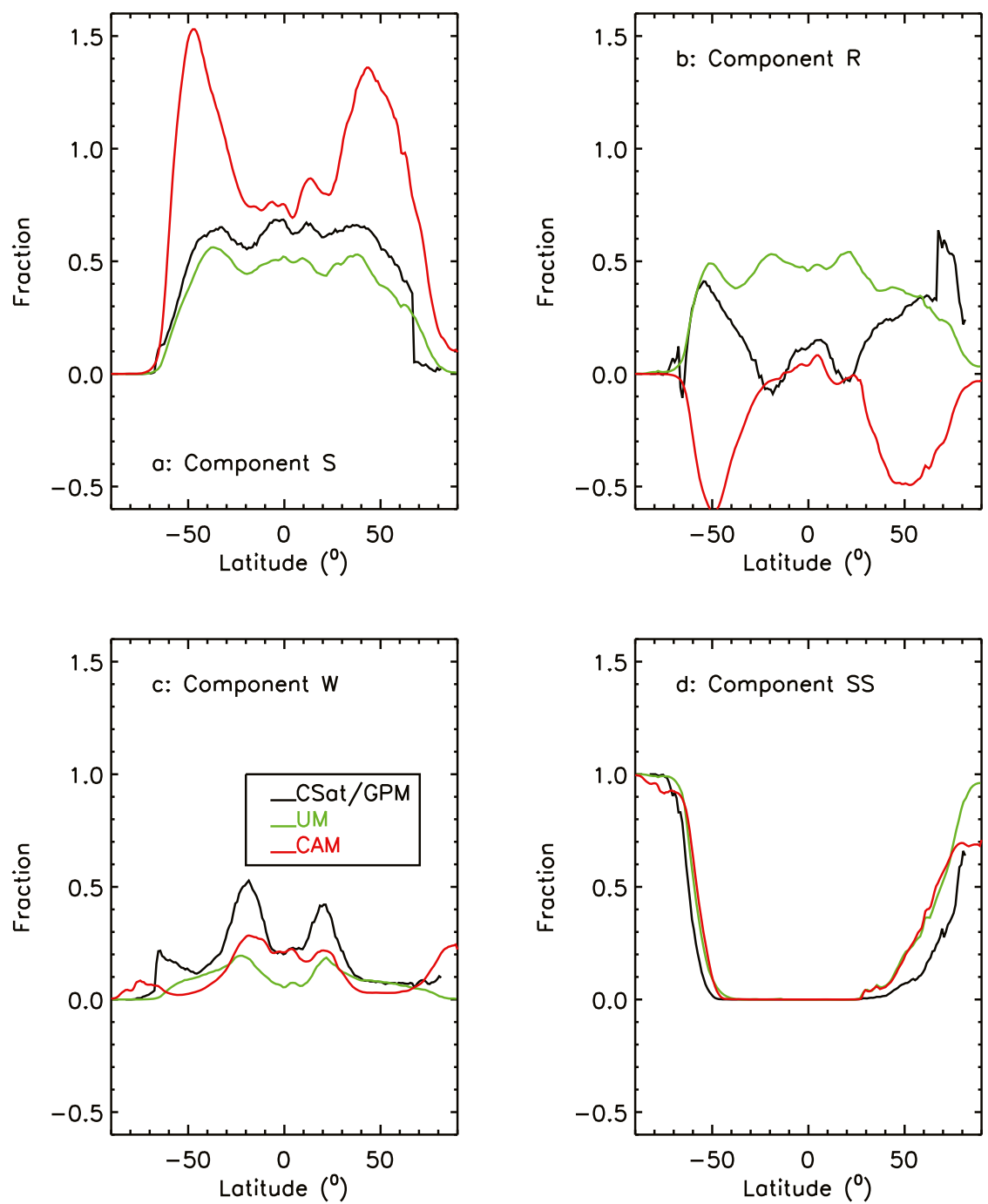

FIG. 11. As in Fig. 10, but for the fraction of each precipitation type compared to the total of all types for each pathway.

higher than the climate model values. The large negative value of $R$ noted for CAM is offset in part by the relatively high value of $W$. The UM produces a relatively large value of SS compared to the satellite-derived product and larger than the CAM value.

\section{b. Estimates of the uncertainties in the radar retrievals}

There are numerous uncertainties in the estimates of the components of the precipitation rate due to inherent limitations of the different radar-based datasets. There are several studies that have discussed uncertainties related to the use of the data sources used here (Hiley et al. 2011; Mülmenstädt et al. 2015; Grecu et al. 2016; Skofronick-Jackson et al. 2019). Table 3 shows the results of global calculations when different datasets were used for our estimates. Row 1 shows the global values calculated from the CPR-GPM combined precipitation dataset to determine $S, R, W$, and SS. If the CPR-GPM dataset was replaced with the GPCP dataset for total precipitation, the results are shown in row 2 . Note that the total is not $100 \%$ as GPCP does not separate surface rain from snow, so this calculation was done by substituting the GPCP values in for total PR. The results of using GPCP rather than CPR-GPM PR leads to a maximum difference of $1.26 \%$. Use of the Skofronick-Jackson et al. (2019) SS parameterization rather than the CPR archived SS values led to a change in SS and $R$ of $0.81 \%$. The Skofronick-Jackson et al. (2019) 


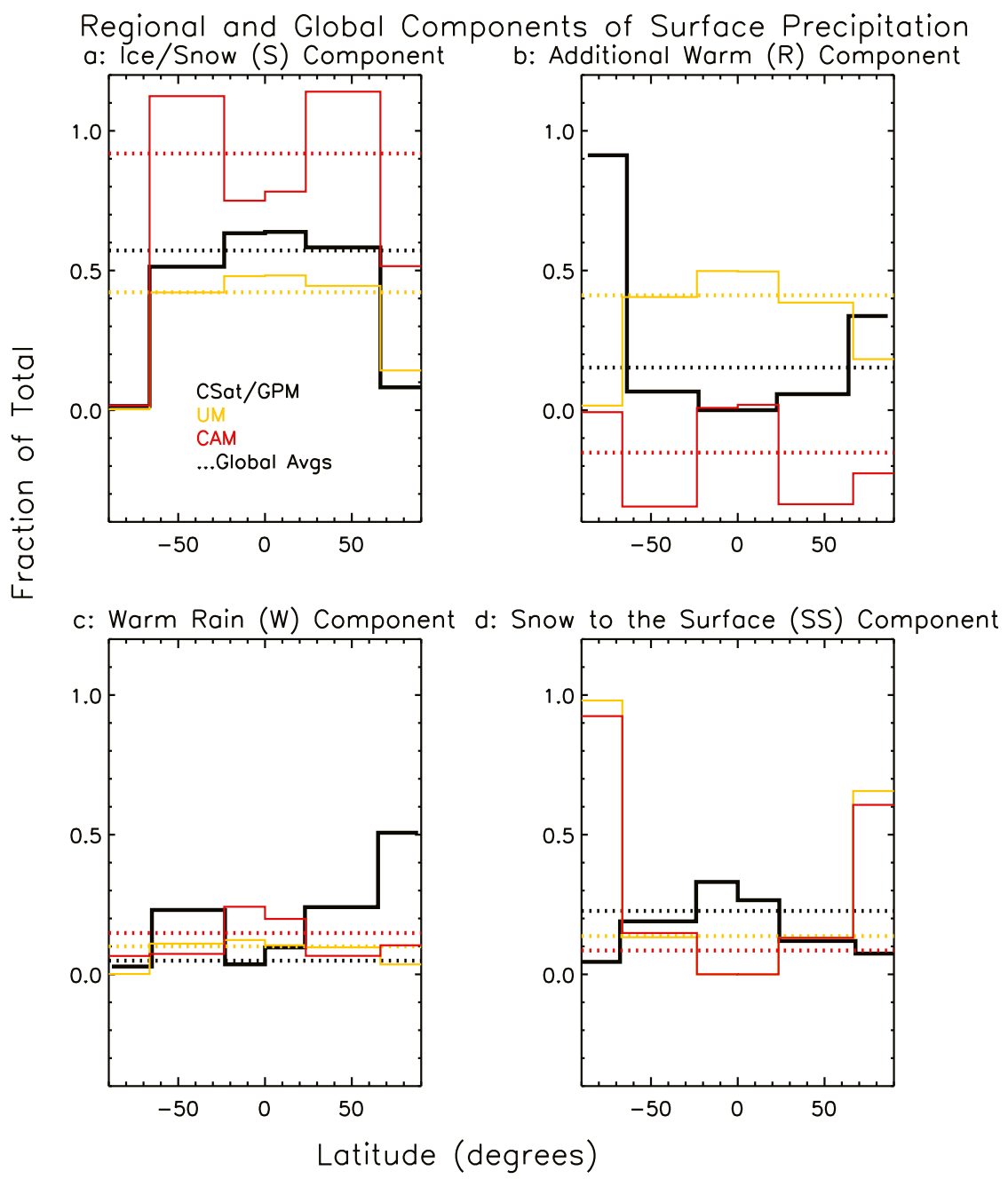

FIG. 12. Regional and global average values of components of precipitation: (a) $S$, (b) $R$, (c) $W$, (d) SS.

rule of eliminating precipitation from $\mathrm{CPR}$ when the reflectivity was higher than $8 \mathrm{dBZ}$ because GPM measurements include those values was also tested. Figure 3 shows global PR calculated with different cutoff values; as can be seen, the $8 \mathrm{dBZ}$ cutoff leads to the best agreement between the CPR-GPM data with GPCP. The difference in the global values of $S, R, W$, and SS using CPR-GPM values with 10 and $12 \mathrm{dBZ}$ cutoffs led to differences of up to $4.2 \%$. Finally, the obvious underestimate caused by neglecting the attenuation parameterization developed for the $\mathrm{H} 18$ relationships led to a final reduction of $4.66 \%$ in $R$. These potential differences due to different dataset inputs, some of them obviously very extreme, led to uncertainties of less than $5 \%$ in all cases suggesting that the overall results are robust enough to compare to climate model results within an uncertainty of $5 \%$.

Adhikari et al. (2018) also looked at uncertainties in SS derived from CPR and GPM. They found that the
GPM Ku-band-derived SS was underestimated by about $51.8 \%$ relative to the use of a combination of CloudSat CPR and GPM Ku-band products. The CPR SS underestimates about $2.3 \%$ of the estimated total snowfall rate.

\section{Summary and conclusions}

The goal of this study is to quantify the modes of precipitation, whether it be snow that melts and later falls to the ground $(S)$, the component added to $S$ at temperatures above where the snow melts $(R)$, warm rain involving on the liquid phase $(W)$, and snow that falls directly to the surface (SS). We used satellite-based radar data (CPR + GPM), the Community Atmosphere Model (CAM) and the Met Office Unified Model (UM) to derive these components of precipitation. Note that other pathways are possible, for example, when melting 


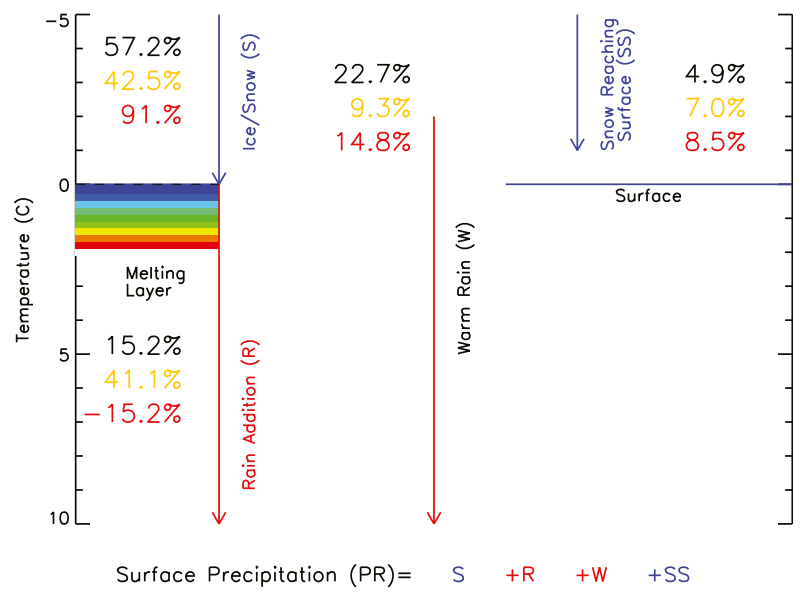

FIG. 13. Schematic showing the different pathways leading to precipitation at the surface, with numbers showing the global average for the satellite and climate model-derived products.

occurs aloft and then the precipitation freezes due to a layer of cold air near the surface, or warm rain produced in combination with snow above the melting layer that falls through the melting layer and is counted as component $S$. Also, the satellite-based datasets-3 years for CloudSat and 2 years for GPM-may not be representative of longer-term datasets. Although the GPCP surface precipitation products for the period 2000-17 indicate relatively little variability in the global surface precipitation rates, with a median of $0.057 \mathrm{~mm} \mathrm{~h}^{-1}$ and a mean and standard deviation of $0.058 \pm 0.0039 \mathrm{~mm} \mathrm{~h}^{-1}$, it is not known how each of the precipitation components may vary by year.

By using the CPR and GPM data in different combinations, we were able to ascertain where each could be used most judiciously to provide the most reliable estimates of the components of precipitation. For CPR, surface precipitation rates (PR) $0.005<\mathrm{PR}<1 \mathrm{~mm} \mathrm{~h}^{-1}$ is the optimal range of precipitation rates over ocean areas for which useful data are obtained. Over land, because the PR are not derived from the CPR retrievals, we had to use methods we developed to retrieve the PR. For GPM, we used the Ku-band retrievals because of their inherent accuracy compared to ether the Ka-band or dual-wavelength retrievals; the useful range is about 0.1 to $30 \mathrm{~mm} \mathrm{~h}^{-1}$. The results for the TRMM retrievals were similar to those for GPM. Although we did not use the GPM radiometer data (GMI), it straddled the PR range for CPR and GPM. We compared the latitudinal estimates of the PR with those from the Global Precipitation Climatology Project (GPCP) product. The agreement between the combination of satellite-based products we used and those of the GPCP product was mostly excellent across the full range of latitudes, the
TABLE 3. Global average fraction of CPR-CAM values of $S, R, W$, and SS calculated using different input values to investigate uncertainty. "Best values" are the global values determined using our analysis. Using GPCP instead of the satellite totals led to a maximum difference of $1.26 \%$ in $S$. Using the Skofronick-Jackson et al. (2019) $Z-S$ relationship led to an increase in SS of $8.4 \%$. Using 10 or $12 \mathrm{dBZ}$ rather than the Skofronick-Jackson et al. (2019)-recommended $8 \mathrm{dBZ}$ cutoff for CPR led to increases of $2.18 \%$ and $4.2 \%$ in $R$, respectively. Neglecting the path-integrated attenuation adjustment to the $\mathrm{H} 18$ result led to a reduction of $R$ by $4.46 \%$.

\begin{tabular}{lcccc}
\hline \hline Uncertainty with different inputs & $S$ & $R$ & $W$ & SS \\
\hline Best values & 0.5952 & 0.1507 & 0.2256 & 0.0285 \\
GPCP instead of satellite totals & 0.5826 & 0.1474 & 0.2209 & 0.0279 \\
Skofronick-Jackson et al. (2019) & 0.5952 & 0.1426 & 0.2256 & 0.0366 \\
$\quad$ instead of archived surface & & & & \\
$\quad$ snow & & & & \\
\hline
\end{tabular}

exception being in the latitude range from about $-20^{\circ}$ to $-60^{\circ}$, thereby suggesting that our PR product and given the sensitivity tests we did suggests that our other products are likely to be reasonably accurate. Furthermore, the global average PR were similar: GPCP, $0.1125 \mathrm{~mm} \mathrm{~h}^{-1}$, and CPR-GPM, $0.1101 \mathrm{~mm} \mathrm{~h}^{-1}$.

The satellite-based products therefore provide a benchmark for determining whether the climate model simulations were reasonable both latitudinally, for regional averages, and for global averages. The component $S$ together with component SS, indicates that most ( $\sim 63 \%$ global mean) of Earth's precipitation comes from the ice phase. The remaining $\sim 37 \%$ is from a combination of water vapor and liquid water added by the component $R$ at temperatures above $0{ }^{\circ} \mathrm{C}$, about $15 \%$, and from warm rain only, at about $23 \%$. A conundrum needing further study is why there is more precipitation generated above the melting layer than below it, even though the water vapor density available for particle growth and thus precipitation development is much larger below the melting layer than above it.

The satellite-based products can be used to assess how reasonable the climate model products are. The global average PR for the $\mathrm{UM}$ was $0.140 \mathrm{~mm} \mathrm{~h}^{-1}$ and for CAM, $0.112 \mathrm{~mm} \mathrm{~h}^{-1}$. These values are very comparable to the GPCP and CPR-GPM products. However, the study revealed that the climate models differed from the satellitebased products in a number of important ways. Although the latitudinal distribution of component $S$ was similar between the satellite retrievals and UM output, the values for CAM output were much larger, across the full range of latitudes. Conversely, although the UM indicated considerably larger values of $R$ than for the satellitebased products, strong negative values were noted for CAM. The latter effect is suggestive of strong evaporation below the melting layer, which seems to 
be nonphysical because the moisture available for condensation is generally high in this zone with further evidence suggesting that there is a relatively large warm rain component. Note, however, that the stratiform precipitation microphysics scheme is two moment, allowing evaporation, whereas the convective scheme is one moment, without evaporation. Future work is needed to further identify the source of the large negative component of $R$ in the application of the two-moment stratiform microphysics scheme. The component SS has the expected result for all three methods that snow reaching the surface dominates the precipitation product in polar regions.

The study provides new precipitation metrics and diagnostics that can be used to evaluate climate models and improve the representation of the water cycle. The primary datasets are archived at https://dashrepo.ucar.edu/ dataset/83_heyms1.html. The comparisons revealed that the climate models differed from the satellite-based products in a way that warrants further investigation that is more forensic than simple traditional surface precipitation differences, providing focused areas of model performance to investigate.

Acknowledgments. NASA supported NCAR investigators for their work on this effort through Grant NNX16AP28G. We wish to thank Norm Wood for helping us with the CloudSat data and Meg Miller for her editorial support. GPCP precipitation data acquired through NOAA/OAR/ESRL PSD, Boulder, Colorado, from their website at https://www.esrl.noaa.gov/psd/.

\section{APPENDIX A}

\section{Evaluation of Collocated CPR-GPM Dataset}

The coincident satellite-based dataset 2B-CSATGPM (Turk 2017, section 2c) is used here to intercompare coincident radar measurements and retrievals for CPR and GPM Ka- and Ku-band measurements, and retrievals based on GMI data. Figure A1a compares CPR W-band reflectivities with those from GPM Ka- and Ku-band measurements. Of all coincidences ( 922000$)$, only those cases where the combination of CPR and GPM Ka bands are chosen for analysis when CPR $-10<$ $Z_{e}<18 \mathrm{~dB}$ and GPM Ka $14<Z_{e}<34 \mathrm{~dB}$ (amounting to $\sim 37000$ coincidences). For GPM Ku band $14<Z_{e}<$ $40 \mathrm{~dB}$ and where $\mathrm{CPR}-10<Z_{e}<18 \mathrm{~dB}$, there are about half that number of collocations $(\sim 19000)$. The ranges are chosen so as to include the GPM minimum detectable reflectivity and an approximate upper limit such that attenuation and non-Rayleigh effects are not too extreme.
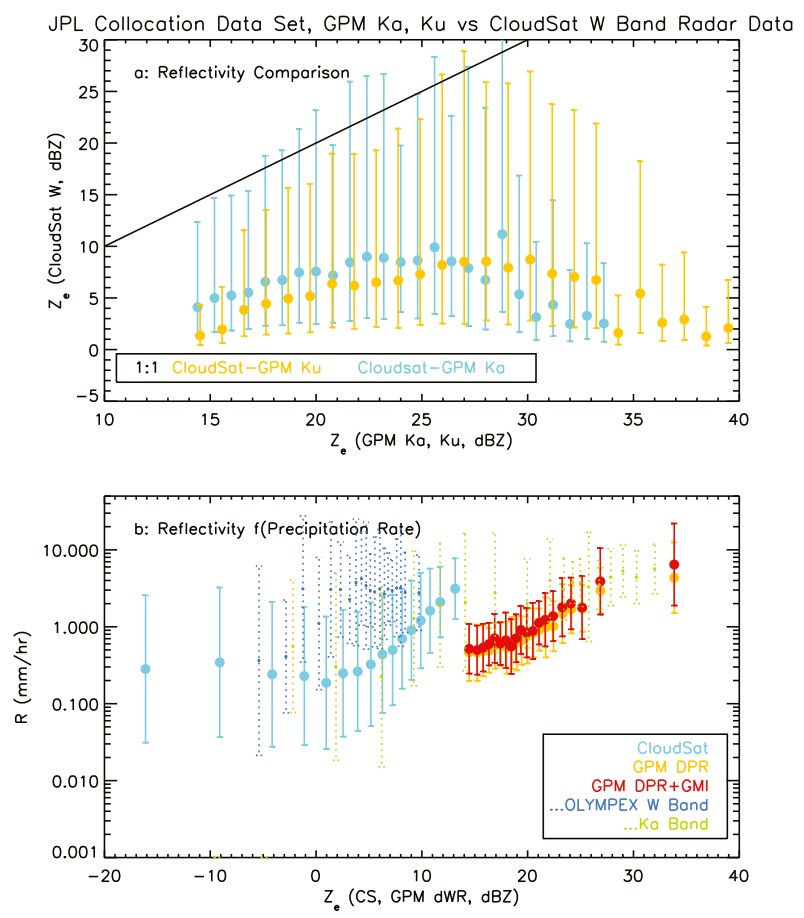

FIG. A1. Analysis of JPL collocated CloudSat-GPM dataset (Turk 2017). (a) Relationship between CloudSat and GPM Kaband radar reflectivities. (b) Relationship between retrieved precipitation-rate product from satellite-based products (shown in legend) and measured radar reflectivity.

At all reflectivities, CPR measurements are considerably below those for GPM. This suggests that in these instances, not surprisingly, attenuation and nonRayleigh scattering at W band is significant (Fig. A1). It is also noted that for CPR reflectivities $>10 \mathrm{~dB}$ and $\mathrm{Ka}$ band reflectivities $>25 \mathrm{~dB}$, the relative difference between CPR and GPM Ka-band radar data markedly increases for the reason that the CPR reflectivities actually decrease. This finding supports the suggestion that there are strong non-Rayleigh scattering effects, and it is consistent with the CPR radar profiles of "dim bands" (Heymsfield et al. 2008). Likewise, "dimming" is suggested by the relative increase in the difference between GPM $\mathrm{Ku}$ and $\mathrm{Ka}$ bands where $Z_{e}>28 \mathrm{~dB}$.

Figure A1b plots the surface precipitation rate (rain) as a function of radar reflectivity using different threshold criteria and data than are used in Fig. A1a. For CPR, $Z_{e}>-20 \mathrm{~dB}$; for GPM DPR (Ka $+\mathrm{Ku}$ band) and GPM DPR + GMI, $>14 \mathrm{~dB}$; threshold surface rain rates were $0.001 \mathrm{~mm} \mathrm{~h}^{-1}$. The rates from the DPR and DPR + GMI are quite close to each other, but differ appreciably from those from CPR rain rate retrieval at nearly overlapping reflectivities. The rates for CPR at the higher reflectivities increase much more steeply with 


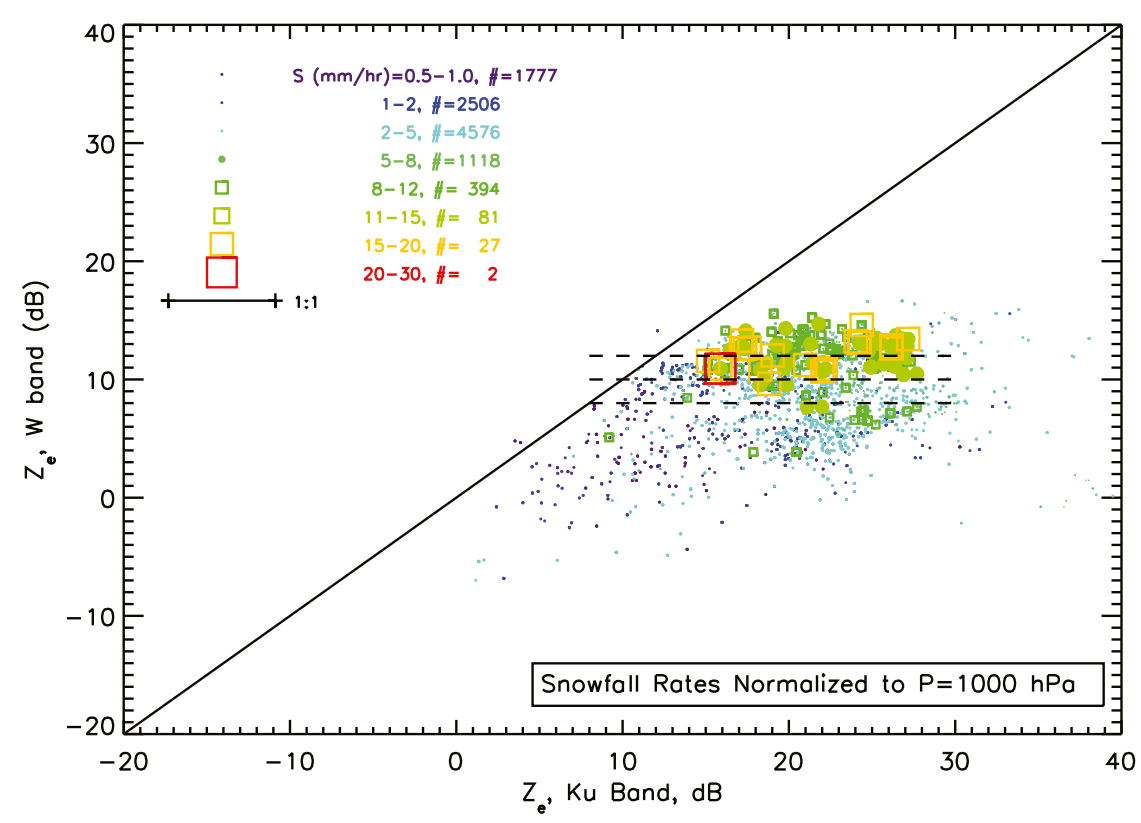

FIG. B1. Comparison of reflectivities at W and Ku bands from the DC-8 APR-3 radar during the OLYMPEX field program at times when the aircraft was overflying the in situ aircraft (see $\mathrm{H} 18)$. Color coded are the snowfall rates derived from the in situ aircraft particle probes. Only those times when the in situ aircraft was not in liquid water regions, that is, with temperatures $<0^{\circ} \mathrm{C}$, are included in the plot.

$Z_{e}$ than do the GPM rates at the lower $Z_{e}$, which may suggest that attenuation is unrealistically affecting the rain-rate retrieval.

\section{APPENDIX B}

\section{Cutoff Reflectivities Used in the Radar Analysis}

Data from the Olympic Mountain Experiment (OLYMPEX) field program are used to evaluate reasonable cutoff reflectivities for CPR and GPM/TRMM. The Airborne Third Generation Precipitation Radar (APR-3) (W, Ka, Ku band) radar system was installed on the NASA DC- 8 aircraft. The DC- 8 was often collocated spatially with the in situ aircraft, which collected microphysical data, from which snowfall rates were derived (H18).

Figure B1 compares the reflectivities from the $\mathrm{Ku}$ band to those for $\mathrm{W}$ band when the DC- 8 was overflying the in situ aircraft. The snowfall rates as derived from the in situ measurements are represented with colorcoded symbols. Only those times when the King Probe on the DC- 8 indicated that there was little if any liquid water are plotted in the figure, to mitigate attenuation of the $\mathrm{W}$-band reflectivity. What is noted is that at $\mathrm{W}$ band, there is a leveling off of the reflectivities relative to those for $\mathrm{Ku}$ band at about $8-10 \mathrm{dBZ}$, such that there is little information content about the snowfall rate at reflectivities above about $10 \mathrm{~dB} Z$.

\section{REFERENCES}

Adhikari, A., C. Liu, and M. Kulie, 2018: Global distribution of snow precipitation features and their properties from three years of GPM observations. J. Climate, 31, 3731-3754, https:// doi.org/10.1175/JCLI-D-17-0012.1.

Adler, R. F., G. Gu, M. Sapiano, J. Wang, and G. J. Huffman, 2017: Global precipitation: Means, variations and trends during the satellite era (1979-2014). Surv. Geophys., 38, 679-699, https:// doi.org/10.1007/s10712-017-9416-4.

Barnett, T. P., J. C. Adam, and D. P. Lettenmaier, 2005: Potential impacts of a warming climate on water availability in snowdominated regions. Nature, 438, 303-309, https://doi.org/ 10.1038/nature04141.

Behrangi, A., M. Lebsock, S. Wong, and B. Lambrigtsen, 2012: On the quantification of oceanic rainfall using spaceborne sensors. J. Geophys. Res., 117, D20105, https://doi.org/10.1029/ 2012JD017979.

_- Y. Tian, B. H. Lambrigtsen, and G. L. Stephens, 2014: What does CloudSat reveal about global land precipitation detection by other spaceborne sensors? Water Resour. Res., 50, 4893-4905, https://doi.org/10.1002/2013WR014566.

Bogenschutz, P. A., A. Gettelman, H. Morrison, V. E. Larson, D. P. Schanen, N. R. Meyer, and C. Craig, 2012: Unified parameterization of the planetary boundary layer and shallow convection with a higher-order turbulence closure in the Community Atmosphere Model: Single-column experiments. Geosci. Model Dev., 5, 1407-1423, https://doi.org/10.5194/ gmd-5-1407-2012. 
Brown, R., and D. Robinson, 2011: Northern Hemisphere spring snow cover variability and change over 1922-2010 including an assessment of uncertainty. Cryosphere, 5, 219-229, https:// doi.org/10.5194/tc-5-219-2011.

Casella, D., G. Panegrossi, P. Sanò, A. C. Marra, S. Dietrich, B. T. Johnson, and M. S. Kulie, 2017: Evaluation of the GPM-DPR snowfall detection capability: Comparison with CloudSat-CPR. Atmos. Res., 197, 64-75, https://doi.org/10.1016/ j.atmosres.2017.06.018.

Catto, J. L., and S. Pfahl, 2013: The importance of fronts for extreme precipitation. J. Geophys. Res. Atmos., 118, $10791-$ 10 801, https://doi.org/10.1002/JGRD.50852.

Feng, S., and Q. Hu, 2007: Changes in winter snowfall/precipitation ratio in the contiguous United States. J. Geophys. Res., 112, D15109, https://doi.org/10.1029/2007JD008397.

Field, P. R., and A. J. Heymsfield, 2015: Importance of snow to global precipitation. Geophys. Res. Lett., 42, 9512-9520, https://doi.org/10.1002/2015GL065497.

$\longrightarrow,-$, and A. Bansemer, 2007: Snow size distribution parameterization for midlatitude and tropical ice clouds. J. Atmos. Sci., 64, 4346-4365, https://doi.org/10.1175/2007JAS2344.1.

Gettelman, A., and H. Morrison, 2015: Advanced two-moment bulk microphysics for global models. Part I: Off-line tests and comparison with other schemes. J. Climate, 28, 1268-1287, https://doi.org/10.1175/JCLI-D-14-00102.1.

Golaz, J.-C., V. E. Larson, and W. R. Cotton, 2002: A PDF-based model for boundary layer clouds. Part I: Method and model description. J. Atmos. Sci., 59, 3540-3551, https://doi.org/ 10.1175/1520-0469(2002)059<3540:APBMFB >2.0.CO;2.

Grecu, M., W. S. Olson, S. J. Munchak, S. Ringerud, L. Liao, Z. Haddad, B. L. Kelley, and S. F. Mclaughlin, 2016: The GPM combined algorithm. J. Atmos. Oceanic Technol., 33, 22252245, https://doi.org/10.1175/JTECH-D-16-0019.1.

Gregory, D., and P. R. Rowntree, 1990: A mass flux convection scheme with representation of cloud ensemble characteristics and stability-dependent closure. Mon. Wea. Rev., 118, 1483-1506, https://doi.org/10.1175/1520-0493(1990)118<1483:AMFCSW > 2.0.CO;2.

Guo, L., and L. Li, 2015: Variation of the proportion of precipitation occurring as snow in the Tian Shan Mountains, China. Int. J. Climatol., 35, 1379-1393, https://doi.org/10.1002/joc.4063.

Gusain, H., V. Mishra, and M. Bhutiyani, 2014: Winter temperature and snowfall trends in the cryospheric region of north-west Himalaya. Mausam, 65, 425-432, https://metnet.imd.gov.in/ mausamdocs/56533.pdf.

Haynes, J. M., T. S. L'Ecuyer, G. L. Stephens, S. D. Miller, C. Mitrescu, N. B. Wood, and S. Tanelli, 2009: Rainfall retrieval over the ocean with spaceborne W-band radar. J. Geophys. Res., 114, D00A22, https://doi.org/10.1029/2008JD009973.

— C. Jakob, W. B. Rossow, G. Tselioudis, and J. Brown, 2011: Major characteristics of Southern Ocean cloud regimes and their effects on the energy budget. J. Climate, 24, 5061-5080, https://doi.org/10.1175/2011JCLI4052.1.

Heymsfield, A. J., A. Bansemer, S. Matrosov, and L. Tian, 2008: The $94-\mathrm{GHz}$ radar dim band: Relevance to ice cloud properties and CloudSat. Geophys. Res. Lett., 35, L03802, https:// doi.org/10.1029/2007GL031361.

, - — , N. B. Wood, G. Liu, S. Tanelli, O. O. Sy, M. Poellot, and C. Liu, 2018: Toward improving ice water content and snow-rate retrievals from radars. Part II: Results from three wavelength radar-collocated in-situ measurements and CloudSatGPM-TRMM radar data. J. Appl. Meteor. Climatol., 57, 365-389, https://doi.org/10.1175/JAMC-D-17-0164.1.
Hiley, M. J., M. S. Kulie, and R. Bennartz, 2011: Uncertainty analysis for CloudSat snowfall retrievals. J. Appl. Meteor. Climatol., 50, 399-418, https://doi.org/10.1175/2010JAMC2505.1.

Hoose, C., J. E. Kristjánsson, J.-P. Chen, and A. Hazra, 2010: A classical-theory-based parameterization of heterogeneous ice nucleation by mineral dust, soot, and biological particles in a global climate model. J. Atmos. Sci., 67, 2483-2503, https:// doi.org/10.1175/2010JAS3425.1.

Houze, R. A., Jr., K. L. Rasmussen, M. D. Zuluaga, and S. R. Brodzik, 2015: The variable nature of convection in the tropics and subtropics: A legacy of 16 years of the Tropical Rainfall Measuring Mission satellite. Rev. Geophys., 53, 994-1021, https://doi.org/10.1002/2015RG000488.

Howat, I. M., and S. Tulaczyk, 2005: Climate sensitivity of spring snowpack in the Sierra Nevada. J. Geophys. Res., 110, F04021, https://doi.org/10.1029/2005JF000356.

Hurrell, J. W., and Coauthors, 2013: The Community Earth System Model: A framework for collaborative research. Bull. Amer. Meteor. Soc., 94, 1339-1360, https://doi.org/10.1175/BAMS-D12-00121.1.

Iguchi, T., T. Kozu, J. Kwiatkowski, R. Meneghini, J. Awaka, and K. Okamoto, 2009: Uncertainties in the rain profiling algorithm for the TRMM Precipitation Radar. J. Meteor. Soc. Japan, 87A, 1-30, https://doi.org/10.2151/jmsj.87A.1.

Knowles, N., M. D. Dettinger, and D. R. Cayan, 2006: Trends in snowfall versus rainfall in the western United States. J. Climate, 19, 4545-4559, https://doi.org/10.1175/JCLI3850.1.

Larson, V. E., J.-C. Golaz, and W. R. Cotton, 2002: Small-scale and mesoscale variability in cloudy boundary layers: Joint probability density functions. J. Atmos. Sci., 59, 3519-3539, https://doi.org/ 10.1175/1520-0469(2002)059<3519:SSAMVI >2.0.CO;2.

Lebsock, M. D., and T. S. L'Ecuyer, 2011: The retrieval of warm rain from CloudSat. J. Geophys. Res., 116, D20209, https:// doi.org/10.1029/2011JD016076.

Liu, C., and E. J. Zipser, 2009: "Warm rain" in the tropics: Seasonal and regional distributions based on nine years of TRMM data. J. Climate, 22, 767-779, https://doi.org/10.1175/2008JCLI2641.1.

Liu, G., 2008: A database of microwave single-scattering properties for nonspherical ice particles. Bull. Amer. Meteor. Soc., 89, 1563-1570, https://doi.org/10.1175/2008BAMS2486.1.

Lock, A. P., A. R. Brown, M. R. Bush, G. M. Martin, and R. N. B. Smith, 2000: A new boundary layer mixing scheme. Part I: Scheme description and single-column model tests. Mon. Wea. Rev., 128, 3187-3199, https://doi.org/10.1175/1520-0493(2000) $128<3187$ :ANBLMS $>2.0$. CO;2.

Marchand, R., G. G. Mace, T. Ackerman, and G. Stephens, 2008: Hydrometeor detection using CloudSat-An Earth-orbiting 94-GHZ cloud radar. J. Atmos. Oceanic Technol., 25, 519-533, https://doi.org/10.1175/2007JTECHA1006.1.

Matus, A. V., and T. S. L'Ecuyer, 2017: The role of cloud phase in Earth's radiation budget. J. Geophys. Res. Atmos., 122, 25592578, https://doi.org/10.1002/2016JD025951.

Meyers, M. P., P. J. DeMott, and W. R. Cotton, 1992: New primary ice-nucleation parameterizations in an explicit cloud model. J. Appl. Meteor., 31, 708-721, https://doi.org/10.1175/15200450(1992)031<0708:NPINPI>2.0.CO;2.

Mülmenstädt, J., O. Sourdeval, J. Delanoë, and J. Quaas, 2015: Frequency of occurrence of rain from liquid-, mixed-, and ice-phase clouds derived from A-Train satellite retrievals. Geophys. Res. Lett., 42, 6502-6509, https://doi.org/10.1002/ 2015GL064604.

Neale, R. B., and Coauthors, 2010: Description of the NCAR Community Atmosphere Model (CAM5.0). NCAR Tech. 
Note NCAR/TN-486+STR, 268 pp., www.cesm.ucar.edu/ models/cesm1.1/cam/docs/description/cam5_desc.pdf.

Salzmann, M., 2016: Global warming without global mean precipitation increase? Sci. Adv., 2, e1501572, https://doi.org/ 10.1126/sciadv.1501572.

Sassen, K., and Z. Wang, 2008: Classifying clouds around the globe with the CloudSat radar: 1-year of results. Geophys. Res. Lett., 35, L04805, https://doi.org/10.1029/2007GL032591.

Seto, S., T. Iguchi, and T. Oki, 2013: The basic performance of a precipitation retrieval algorithm for the Global Precipitation Measurement Mission's single/dual-frequency radar measurements. IEEE Trans. Geosci. Remote Sens., 51, 5239-5251, https://doi.org/10.1109/TGRS.2012.2231686.

Sindhu, K. D., and G. S. Bhat, 2013: Comparison of CloudSat and TRMM radar reflectivities. J. Earth Syst. Sci., 122, 947-956, https://doi.org/10.1007/s12040-013-0316-9.

Skofronick-Jackson, G., M. Kulie, L. Milani, J. Munchak, N. B. Wood, and V. Levizzani, 2019: Satellite estimation of falling snow: A Global Precipitation Measurement (GPM) Core Observatory perspective. J. Appl. Meteor. Climatol., 58, 14291448, https://doi.org/10.1175/JAMC-D-18-0124.1.

Sun, Q., C. Miao, Q. Duan, H. Ashouri, S. Sorooshian, and K.-L. Hsu, 2018: A review of global precipitation data sets: Data sources, estimation, and intercomparisons. Rev. Geophys., 56, 79-107, https://doi.org/10.1002/2017RG000574.

Tamang, S. K., A. M. Ebtehaj, A. F. Prein, and A. J. Heymsfield, 2019: Linking global changes of snowfall and wet-bulb temperature. J. Climate, 33, 39-59, https://doi.org/10.1175/ JCLI-D-19-0254.1.

Trenberth, K. E., and D. P. Stepaniak, 2003a: Covariability of components of poleward atmospheric energy transports on seasonal and interannual timescales. J. Climate, 16, 3691-3704, https:// doi.org/10.1175/1520-0442(2003)016<3691:COCOPA >2.0.CO;2.

$\longrightarrow$, and $-2003 \mathrm{~b}$ : Seamless poleward atmospheric energy transports and implications for the Hadley circulation. J. Climate, 16, 3706-3721, https://doi.org/10.1175/1520-0442(2003)016<3706: SPAETA $>2.0 . \mathrm{CO} ; 2$.

, J. M. Caron, and D. P. Stepaniak, 2001: The atmospheric energy budget and implications for surface fluxes and ocean heat transports. Climate Dyn., 17, 259-276, https://doi.org/ 10.1007/PL00007927.

Turk, J., 2016: CloudSat-GPM coincidence dataset, version 1C. NASA Tech. Rep., 18 pp., https://pmm.nasa.gov/sites/default/ files/document_files/CSATGPM_COIN_ATBD.pdf.

- 2017: CloudSat-GPM coincidence dataset, version 2A. NASA Tech. Memo., 23 pp., https://pps.gsfc.nasa.gov/Documents/ CSATGPM_COIN_ATBD.pdf.

Valt, M., and C. Paola, 2013: Climate change in Italian alps: Analysis of snow precipitation, snow durations and avalanche activity. Int. Snow Sci. Workshop, Grenoble-Chamonix Mont-Blanc, France, International Snow Science Workshop, 1247-1250.

Walters, D. N., and Coauthors, 2017: The Met Office Unified Model global atmosphere 6.0/6.1 and JULES global land 6.0/6.1 configurations. Geosci. Model Dev., 10, 1487-1520, https://doi.org/10.5194/gmd-10-1487-2017.

Wang, J., M. Zhang, S. Wang, Z. Ren, Y. Che, F. Qiang, and D. Qu, 2016: Decrease in snowfall/rainfall ratio in the Tibetan Plateau from 1961 to 2013. J. Geogr. Sci., 26, 1277-1288, https:// doi.org/10.1007/s11442-016-1326-8.

Wang, X., G. Huang, and J. Liu, 2014: Projected increases in intensity and frequency of rainfall extremes through a regional climate modeling approach. J. Geophys. Res. Atmos., 119 , 13 271-13 286, https://doi.org/10.1002/2014JD022564.

Wilson, D. R., and S. P. Ballard, 1999: A microphysically based precipitation scheme for the UK Meteorological Office Unified Model. Quart. J. Roy. Meteor. Soc., 125, 1607-1636, https:// doi.org/10.1002/qj.49712555707.

, A. C. Bushell, A. M. Kerr-Munslow, J. D. Price, and C. J. Morcrette, 2008: PC2: A prognostic cloud fraction and condensation scheme. I: Scheme description. Quart. J. Roy. Meteor. Soc., 134, 2093-2107, https://doi.org/10.1002/ qj.333.

Yin, M., G. Liu, R. Honeyager, and F. J. Turk, 2017: Observed differences of triple-frequency radar signatures between snowflakes in stratiform and convective clouds. J. Quant. Spectrosc. Radiat. Transfer, 193, 13-20, https://doi.org/10.1016/ j.jqsrt.2017.02.017. 